\title{
Entre cerros y cañadones. Avances sobre el plano arqueológico del sitio Fuerte San José (Península Valdés, Chubut)
}

Marcia Bianchi Villelli*, Silvana Buscaglia**, Paula D. Calandrón*** y Anabella G. Sellanes***
Recibido:

14 de marzo de 2018

Aceptado:

27 de junio de 2018

\begin{abstract}
Resumen
El objetivo de este trabajo es presentar el plano arqueológico del sitio Fuerte San José (Península Valdés, Chubut), integrando los análisis de documentación histórica y cartográfica con los resultados de las tres campañas arqueológicas realizadas al sitio. La fragmentación y ambigüedad de la información histórica, así como la baja obstrusividad del registro arqueológico, promovieron que las investigaciones en el Fuerte San José se centren en examinar cómo se organizó el espacio y se habitó dicho asentamiento colonial. En tanto esta condición lo vuelve un caso atípico y complejo en el marco de las investigaciones en arqueología histórica, presentamos en este trabajo el diseño metodológico para abordar la estructuración y uso del espacio donde se habría emplazado el fuerte colonial, atendiendo a los procesos de formación que afectan al sitio, sus consecuencias para el registro arqueológico y la preservación del patrimonio local.
\end{abstract}

\section{Between hills and gullies. Advances in the archaeological site plan of San José Fort (Península Valdés, Chubut)}

\footnotetext{
Abstract

This study presents the archaeological site plan from San José Fort site (Península Valdés, Chubut). The plan is the result of an integration of historical and cartographic documentation, complemented by the archaeological results from three field seasons. One of the main questions that guided this research referred to how space was organized and inhabited in this particular colonial settlement, especially given that the historical

* Instituto de Investigaciones en Diversidad Cultural y Procesos de Cambio (IIDYPCA), Universidad Nacional de Río Negro (UNRN) - CONICET. Bartolomé Mitre 630, $5^{\circ}$ Piso (CP R8400AHN) San Carlos de Bariloche, Río Negro, Argentina. E-mail: bianchi.marcia@gmail.com

** Instituto Multidisciplinario de Historia y Ciencias Humanas (IMHICIHU), CONICET. Saavedra 15, $5^{\circ}$ piso (CP

C1083ACA) Ciudad Autónoma de Buenos Aires, Argentina. E-mail: silvana_buscaglia@yahoo.com.ar

*** Departamento de Ciencias Antropológicas, Facultad de Filosofía y Letras, Universidad de Buenos Aires (UBA). Puan 480, $3^{\circ}$ piso (CP C1406CQJ) Ciudad Autónoma de Buenos Aires, Argentina. E-mail: paulacalandron@gmail.com; annasellanes@gmail.com
}

\section{Keywords}

Eighteenth-Nineteenth centuries San José Fort Patagonian coast Historical archaeology Colonial spatial organization

\section{Siglos XVIII-XIX Fuerte San José Costa patagónica Arqueología histórica Estructuración del espacio colonial \\ Palabras clave}

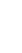


data was fragmented and ambiguous, while the archaeological record was unobtrusive. This makes San José Fort a rare and complex case in historical archaeology. Here we present our methodological approach for examining the organization and use of this colonial space, focusing on the natural formation processes that affected the site, and the consequences of this for the archaeological record and the preservation of local heritage.

\section{Introducción}

El Fuerte San José (Península Valdés, provincia de Chubut) es objeto de investigaciones históricas y arqueológicas desde el año 2010, cuando se inició el proyecto "Primeros abordajes arqueológicos al Fuerte San José y Manantiales Villarino, Península Valdés, Chubut (1779-1810)". Dicho proyecto tiene por objeto discutir la conformación del paisaje colonial en Península Valdés desde la perspectiva de la arqueología histórica, atendiendo a la intersección de estrategias coloniales e indígenas y contribuir de este modo a ampliar la discusión sobre el proceso de colonización de la costa patagónica.

El sitio arqueológico Fuerte San José se encuentra emplazado en la costa sudeste del Golfo homónimo, a unos $200 \mathrm{~m}$ de la línea de costa y la actual Playa Fracasso (Figura 1A). Como ya hemos desarrollado en otros artículos, el fuerte fue el primer asentamiento creado como parte del plan de colonización español de la costa atlántica patagónica a fines del siglo XVIII - en la Figura 1B se observa el detalle de uno de los primeros mapas de la península con una representación esquemática del fuerte(Buscaglia y Bianchi Villelli, 2016; Buscaglia et al., 2012). Casi de manera simultánea se crea el Puesto de la Fuente, un asentamiento de carácter productivo y complementario al Fuerte San José, situado a unos $30 \mathrm{~km}$ de éste sobre el ángulo sudoeste de la denominada Salina Grande (estancia Manantiales, Península Valdés, provincia de Chubut). El lapso de ocupación de los asentamientos se extendió desde 1779 hasta 1810, año en el que ambos fueron incendiados y destruidos como consecuencia de un ataque indígena (Aragón, 1810) que produjo la muerte de la mayor parte de sus ocupantes (Bianchi Villelli, 2017; Buscaglia, 2017; Buscaglia y Bianchi Villelli, 2016; entre otros).

Desde el punto de vista ambiental, es importante destacar que el sitio se encuentra en un área con baja cobertura vegetal y especies xerófilas con un proceso de desertificación avanzado. Esta situación se agudiza con la erosión eólica e hídrica, particularmente a causa de las fuertes lluvias estacionales que lavan el suelo y producen constantemente cárcavas que se profundizan y extienden, atravesando concentraciones arqueológicas y re-depositándolas. Sumado a ello, es necesario considerar la historia de las intervenciones arqueológicas, así como también aquellas asistemáticas realizadas por aficionados y visitantes a lo largo del tiempo. En consecuencia, el sitio arqueológico presenta un comprometido estado de preservación en tanto los factores de deterioro naturales como culturales permanecen activos.

Península Valdés cuenta con una larga historia ocupacional que se remonta desde el Holoceno medio hasta la actualidad, evidenciándose un abandono progresivo de la explotación de los recursos de la costa por parte de las poblaciones indígenas hacia el período post-contacto (Banegas, Goye y Gómez Otero, 2015; Belardi, 2005; Gómez Otero, 2006; Gómez Otero, Belardi, Súnico y Taylor, 1999; Gómez Otero, Schuster y Banegas, 2017; Moreno y Videla, 2008, entre otros). Las investigaciones realizadas por la Dra. Gómez Otero y equipo así como las propias han arrojado evidencia relacionada con materiales de origen indígena en el área del Fuerte San José. Los mismos datarían del período Post-contacto, aunque por el momento no es posible establecer si guardan alguna relación con la ocupación española. Esta característica imprime al espacio 

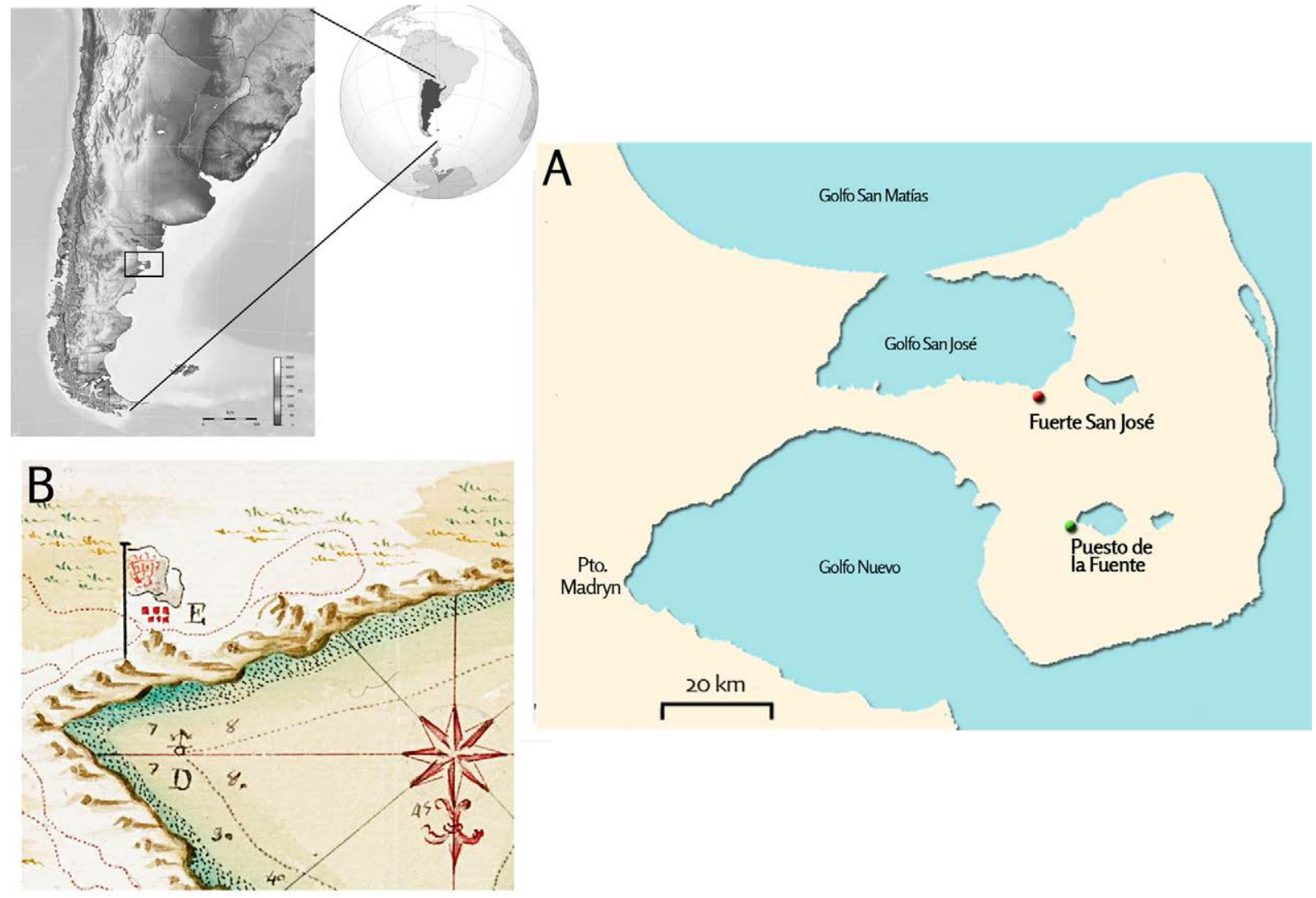

Figura 1. A) localización de Fuerte San José y el Puesto de la Fuente (Península Valdés, provincia de Chubut, Argentina); B) "configuración (mapa) del Puerto de San José" de Pedro García, 1779 - contiene el mayor detalle gráfico de las construcciones hallado hasta el momento.

relacionado con la ocupación colonial del fuerte y sectores aledaños, una complejidad extra a la hora de evaluar la resolución y la integridad del registro arqueológico.

La presencia estable de europeos en Península Valdés se relaciona con el plan de poblamiento de la costa patagónica desarrollado a fines del siglo XVIII (Apolant, 1970; Luiz, 2006; Senatore, 2007; entre otros) cuando en 1779 se funda el Fuerte San José. A tan sólo dos años de la destrucción del fuerte, una parte de éste fue reocupado en el marco de las expediciones loberas y ganaderas (1812-1823) organizadas por Henry Libanus Jones (Jones 1855 en Dumrauf, 1991).

Entre 1905 y 1916, y como parte del poblamiento de Península Valdés, funcionó en el área el poblado de Puerto San José, con una población de aproximadamente 100 habitantes que se instaló en una planicie a unos $200 \mathrm{~m}$ al este del fuerte (Barba Ruiz, 2000; Fernández, Gavirati y Jones, 2008; Suplemento ilustrado Golfo Nuevo, 2003). Tanto en este caso como en las expediciones de Libanus Jones, los testimonios dan cuenta de la extracción y reutilización de materiales del fuerte.

Un capítulo importante en la historia del fuerte lo representan las intervenciones asistemáticas realizadas en el sitio arqueológico en las décadas de 1970 y 1980 cuando la Comisión Honoraria de Estudios Históricos del Fuerte San José propuso un proyecto de investigación y de réplica del Fuerte San José. Como parte de este proyecto se realizaron excavaciones en diversos sectores del fuerte (Lanoël, Barba Ruiz, Zapatero y Gutiérrez Neri, 1974), hasta que en la década de 1980 se descubrió un área con enterratorios (Jorge Depasquali, comunicación personal). Por último, es importante señalar que en 
las últimas décadas la Playa Fracasso es un lugar de acceso público, visitado tanto por turistas como por trabajadores vinculados al oficio de la pesca y el marisqueo artesanal.

Todos estos factores ambientales y culturales, sumado el registro de pozos de huaqueo desde el año 2010 en adelante, alertan sobre la complejidad y la vulnerabilidad del sitio arqueológico desde el punto de vista de las actividades antrópicas, a pesar de haber sido declarado monumento histórico (Decreto No 3911/1977) y de encontrarse en un área protegida declarada Patrimonio de la Humanidad por la Unesco en 1999 (Gómez Otero, 2006; Gómez Otero et al., 1999; Plan de Manejo del Área Protegida de Península Valdés, s/f).

\section{Abordaje histórico y arqueológico al Fuerte San José}

Sobre la base del análisis e integración de documentación histórica - fuentes escritas y cartográficas-, relevamientos topográficos, prospecciones de superficie y excavaciones arqueológicas resultantes de tres campañas realizadas en el sitio entre los años 2010 y 2014, presentamos el plano arqueológico del Fuerte San José. Dicho plano es una herramienta que permite integrar los diversos rasgos arqueológicos observados en superficie y sub-superficie así como evaluar los procesos de formación naturales y culturales. De este modo, es posible poner la ocupación colonial de Península Valdés en contexto con las precedentes de cazadores-recolectores así como con las posteriores, vinculadas principalmente a la explotación ganadera, lobera y salinera de la península entre los siglos XIX y XX.

Partiendo de los antecedentes existentes para el Fuerte Nuestra Señora del Carmen (Carmen de Patagones, provincia de Buenos Aires), la Nueva Colonia y Fuerte de Floridablanca (Puerto San Julián, provincia de Santa Cruz) y el Establecimiento de la Real Compañía Marítima (Puerto Deseado, provincia de Santa Cruz), los asentamientos coloniales patagónicos de fines del siglo XVIII podrían pensarse como núcleos poblacionales discretos, con cierta complejidad arquitectónica y una alta modificación del medio circundante - tanto desde el punto de vista material como productivo-. Sin embargo, como se desarrollará en este trabajo, el Fuerte San José pudo haber sido más la excepción que la regla.

Desde el comienzo, uno de los grandes interrogantes que han guiado las investigaciones en el Fuerte San José se relaciona con la forma en que se organizó y habitó el espacio en dicho asentamiento colonial, fundamentalmente debido a la escasez y la ambigüedad de la información histórica sobre este aspecto - a diferencia de los otros asentamientos-, así como la baja obstrusividad de rasgos y estructuras en el terreno. Esta condición lo vuelve un caso atípico y complejo en el marco de las investigaciones en arqueología histórica. En particular, en lo que hace a la integración de distintas estrategias en el diseño metodológico con el fin de abordar la estructuración y el uso del espacio donde se habría emplazado el fuerte colonial.

\section{Metodología y líneas de evidencia}

Como se desarrollará a continuación, la complejidad tanto del registro histórico como arqueológico implicó la integración, confrontación y discusión crítica de múltiples líneas de evidencia con el fin de poder aproximarnos a una interpretación de la estructuración del espacio en el Fuerte San José y así, generar el primer plano arqueológico del sitio.

Desde el punto de vista de la evidencia histórica, la dispersión, la fragmentariedad y los vacíos de información, así como las confusiones históricas existentes en torno a los "planos" del fuerte, no sólo implicaron evaluar críticamente las fuentes documentales 
sino el proceso mismo de catalogación en los repositorios donde se encuentran éstas (Bianchi Villelli, Buscaglia y Sancci, 2013). Es importante mencionar que como parte de las pesquisas realizadas hasta el momento se ha reunido un corpus muy extenso de fuentes primarias - éditas e inéditas - y antecedentes bibliográficos procedentes de archivos y bibliotecas tanto nacionales como extranjeras, principalmente el Archivo General de la Nación (en adelante AGN).

En cuanto a la evidencia arqueológica, la ausencia o escasa obstrusividad de posibles estructuras arquitectónicas determinó que el abordaje espacial integrara información topográfica mediante el uso de nivel óptico y GPS, empleo de detector de metales, mapeo de la cobertura vegetal, prospecciones de superficie y excavaciones arqueológicas con el objeto de evaluar la distribución diferencial, las características y la preservación de los diversos tipos de materiales arqueológicos en el espacio. Los análisis de laboratorio estuvieron orientados principalmente al inventario y análisis total de los materiales, considerándose variables específicas a cada categoría artefactual a los efectos de realizar su clasificación a nivel tecnotipológico, morfológico y funcional. Asimismo, se registró información correspondiente al estado de preservación, agentes y procesos postdepositacionales.

La información espacial y arqueológica también fue procesada mediante el entorno SIG que integra estos datos en una cartografía digital a partir de su georreferenciación. Una de las principales dificultades para trabajar el sitio es que las planimetrías existentes tienen una escala menor al detalle del sitio - se revisaron cartas topográficas del Instituto Geográfico Nacional (IGN) de la península, fotos áreas, imágenes satelitales nacionales y extranjeras, así como los modelos de elevación digital-. En consecuencia, decidimos operativizar el análisis con un mapa-esquema, resultado del relevamiento topográfico con GPS mediante transectas extendidas por todo el sitio. Dicho esquema representa los desniveles del área, pero no constituye un plano topográfico en tanto los valores de altitud son estimados y no reales; no obstante, resultó operativo para abordar las dimensiones espaciales, las diferencias de altitud y las pendientes, así como una interfaz de representación gráfica.

\section{Resultados de la compulsa de fuentes históricas}

Sólo existen mapas de los primeros dos años de funcionamiento del fuerte. En la figura 1B se muestra un recorte de uno de los mapas de 1779, en el que se simboliza a San José como un conjunto de estructuras cuadrangulares aisladas. Dicha representación se reiterará en los mapas subsiguientes sin mayores precisiones ni modificaciones, resultando más en una marca de localización que en una descripción arquitectónica —dicho mapa se publicó completo en Bianchi Villelli et al. (2013) - . Por otro lado, la única y más completa descripción textual sobre la organización espacial y las estructuras que integraron el fuerte, data de momentos iniciales del asentamiento. En ella se describe situada entre dos pequeños cerros:

una plazuela cerrada con cuatro frentes de los que uno es un almacén grande de víveres, y repuestos, otros cuarteles; y los otros dos cuartos, y Capilla. A la parte exterior hay dos Hospitales, cocinas y en uno de los cerritos se ven principios de un fuerte cuadrado por la figura de una mala zanja construida para este fin, pero de ninguna defensa, y a parte hay un Almacén de Pólvora (Soler y García, 1779, pp. 1042-1043).

Fuera de este documento, solo se han registrado oficios de forma dispersa en los que se mencionan tiendas de palos y cuero, uso de paja y adobe, así como reiterados pedidos de albañiles y ladrillos para superar las condiciones de precariedad, solicitudes que 
escasas veces fueron atendidas. Aisladamente, en los documentos podemos recuperar algunas de las estructuras y sus características - capilla con techo de paja, almacenes de cuero y madera de sauce, habitaciones de cuero, baluartes- que formaron parte del fuerte, pero sin brindar más información sobre su ubicación y relación en el espacio. A su vez, en un oficio de Antonio Viedma de agosto de 1779, registramos la única mención a un camposanto del fuerte en los 31 años que duró su ocupación. Allí fueron enterrados 24 individuos fallecidos por escorbuto. Hasta el momento constituye la única referencia a un cementerio, aunque se omite mencionar su ubicación y organización (Viedma, 1779).

A pesar que el fuerte perduró 31 años, la precariedad en las condiciones de vida y el carácter temporario de los espacios de habitación destinados a la población fueron un problema nunca resuelto (Bianchi et al., 2013; Buscaglia y Bianchi Villelli, 2016). Esta imagen de precariedad es en parte corroborada por el relato de Libanus Jones, quien describe en su diario diversas estructuras que formaron parte del fuerte en la costa como por ejemplo "un rancho o cuartel" con techo de paja sobre el cerrito, por debajo una capilla construida en adobe y techada también con paja, y muy cerca de la playa una edificación de adobe, techo de tejas y horno que Jones asigna a la panadería. Esta última fue reutilizada por los expedicionarios para guardar víveres y almacenar cueros de lobos marinos (Jones 1855 en Dumrauf, 1991, pp. 72-80).

\section{Relevamientos arqueológicos}

El Fuerte San José se encuentra emplazado sobre la costa sudeste del Golfo San José, en un sector conformado por acantilados y paleoacantilados altos y una playa que alterna planicies de mareas con restingas (Gómez Otero, 2006, p. 149). Cabe mencionar que el sustrato en este sector de la costa de la península corresponde a la Formación Puerto Madryn, originada durante la última transgresión marina en el Mioceno tardío y compuesta por sedimentitas, con abundante y diverso contenido fósil — tanto de origen marino como terrestre-, así como por depósitos aluviales y coluviales del Holoceno (Belardi, 2005; Cuitiño et al., 2017; Haller, 2017).

Entre los años 2010 y 2014, las prospecciones y excavaciones realizadas en el sitio permitieron definir seis sectores con evidencias de modificación antrópica y/o presencia colonial (Figura 2 y Tabla 1), ninguno de los cuales tendría correspondencia con lo representado en el mapa de la Figura 1B, aunque sí con el relato de Manuel Soler antes detallado. Por otra parte, se relevaron los rasgos asociados a las transformaciones del sitio posteriores al asentamiento colonial, y concentraciones artefactuales relacionadas con posibles usos de cazadores-recolectores.

En la Figura 3 puede observarse una vista del sitio arqueológico con la demarcación de los sectores sobre el paisaje actual. El sector San José 1 (SJ1) se encuentra emplazado al pie de dos cerros al borde de un cañadón y consiste en un denso parche de vegetación de forma cuadrangular, levemente sobre-elevado que contrasta con la baja cobertura vegetal circundante. En este sector observamos una abundante presencia de materiales arqueológicos en superficie, muchos de ellos asignables a fines del siglo XVIII - locus SJ1. San José 2 (SJ2) se encuentra situado sobre el cerrito del lado norte, definido por una zanja perimetral de $17 \times 20 \mathrm{~m}$, con materiales coloniales en superficie y dos pozos que podrían ser producto del huaqueo. San José 3 (SJ3) se ubica sobre el extremo Este del mismo cerrito y corresponde a un pozo rectangular excavado sobre la roca madre de $4,5 \mathrm{~m}^{2}$, con los cimientos de una pared de adobe - erosionado- sobre sus bordes. San José 4 (SJ4) corresponde al sector donde se hallaron restos humanos enterrados. Este sector se ubica en la parte alta de la herradura entre cerros, en una zona medanosa. San José 5 (SJ5) es el área de la ladera norte del cerrito norte y se caracteriza por la 


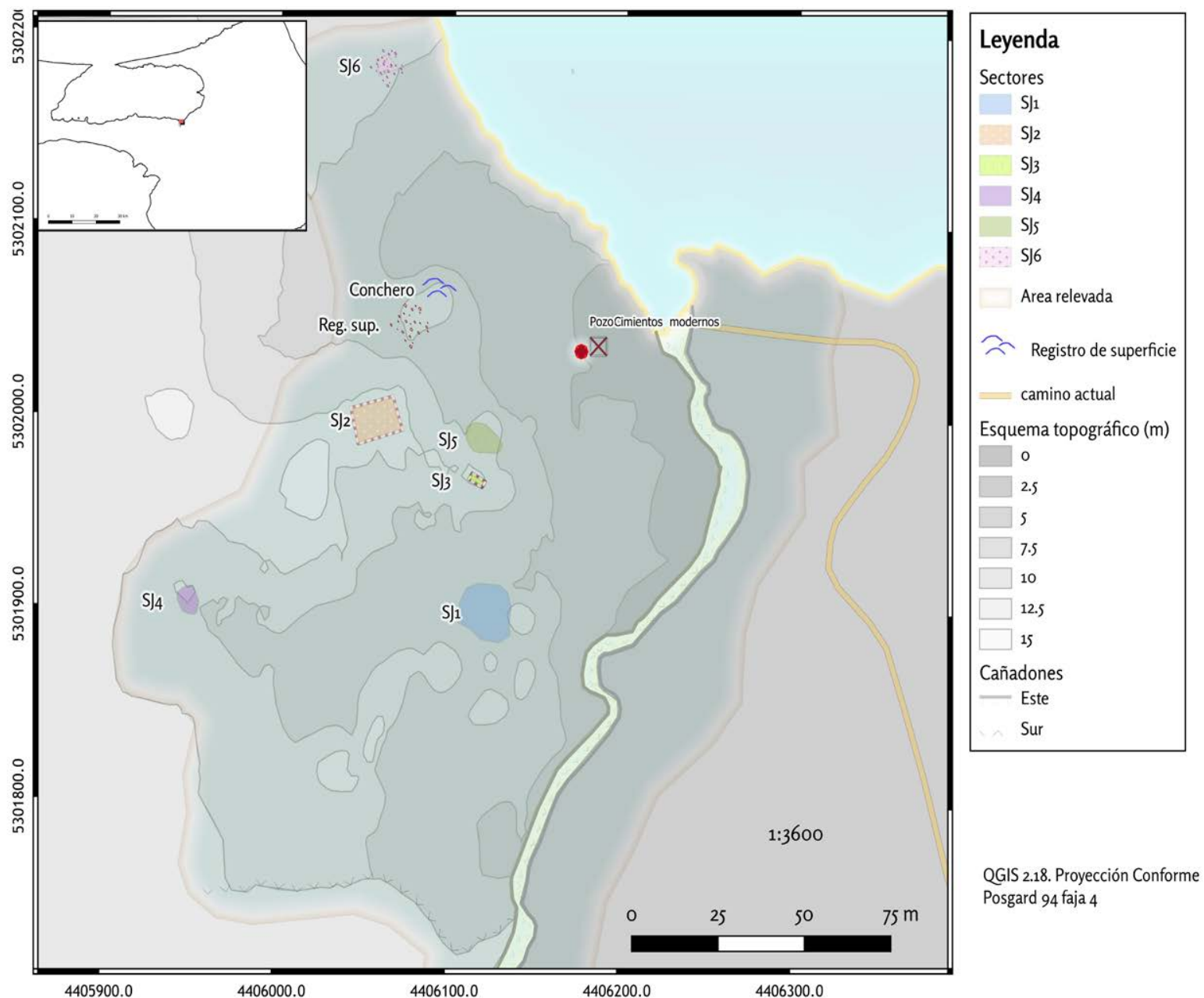

Figura 2. Mapa del sitio arqueológico Fuerte San José. Se demarca el área prospectada -sombreada - con la localización de sectores presentados en el trabajo.

\begin{tabular}{|c|c|c|c|c|c|c|c|c|c|c|c|c|}
\hline & \multicolumn{2}{|c|}{ Cerámica } & \multicolumn{2}{|c|}{ Metal } & \multicolumn{2}{|c|}{ Vidrio } & \multicolumn{2}{|c|}{ Lítico } & \multicolumn{2}{|c|}{$\begin{array}{c}\text { Restos } \\
\text { arqueofaunísticos }\end{array}$} & \multicolumn{2}{|c|}{ Total } \\
\hline & absol. & $\%$ & absol. & $\%$ & absol. & $\%$ & absol. & $\%$ & absol. & $\%$ & absol. & $\%$ \\
\hline SJ1 & 646 & 17,3 & 344 & 9,2 & 161 & 4,3 & 15 & 0,2 & 2.559 & 68,9 & 3.729 & 59 \\
\hline SJ2 & $\mathrm{o}$ & o & 15 & 71,4 & 1 & 4,8 & $\mathrm{o}$ & o & 5 & 23,8 & 21 & 0,3 \\
\hline $\mathrm{SJ}_{3}$ & $\mathrm{o}$ & o & o & o & 0 & 0 & $\mathrm{o}$ & o & $\mathrm{o}$ & $\mathrm{o}$ & o & o \\
\hline $\mathrm{SJ}_{4}$ & 2 & 50 & 2 & 50 & $\mathrm{o}$ & $\mathrm{o}$ & $\mathrm{o}$ & o & o & $\mathrm{o}$ & 4 & 0,1 \\
\hline Sl5 & 53 & 2,4 & 37 & 1,6 & 14 & 0,6 & 5 & 0,2 & 2.146 & 95,2 & 2.253 & 36 \\
\hline SJ6 & 42 & 18,8 & 162 & 72,6 & 3 & 1,3 & 5 & 2,2 & 11 & 4,9 & 223 & 3,5 \\
\hline Cañadón Este & 4 & 6 & 49 & 73,1 & 5 & 7,5 & 2 & 3 & 7 & 10,4 & 67 & 1,1 \\
\hline Cañadón Sur & 1 & 11,1 & 1 & 11,1 & 4 & 44,4 & 1 & o & 7 & 33,3 & 9 & 0,1 \\
\hline Total & 748 & 11,9 & 610 & 9,7 & 188 & 3 & 28 & 0,3 & 4.743 & 75,2 & 6.306 & 100 \\
\hline
\end{tabular}

Tabla 1. Abundancia y diversidad de la cultura material recuperada en distintos sectores del Fuerte San José. 


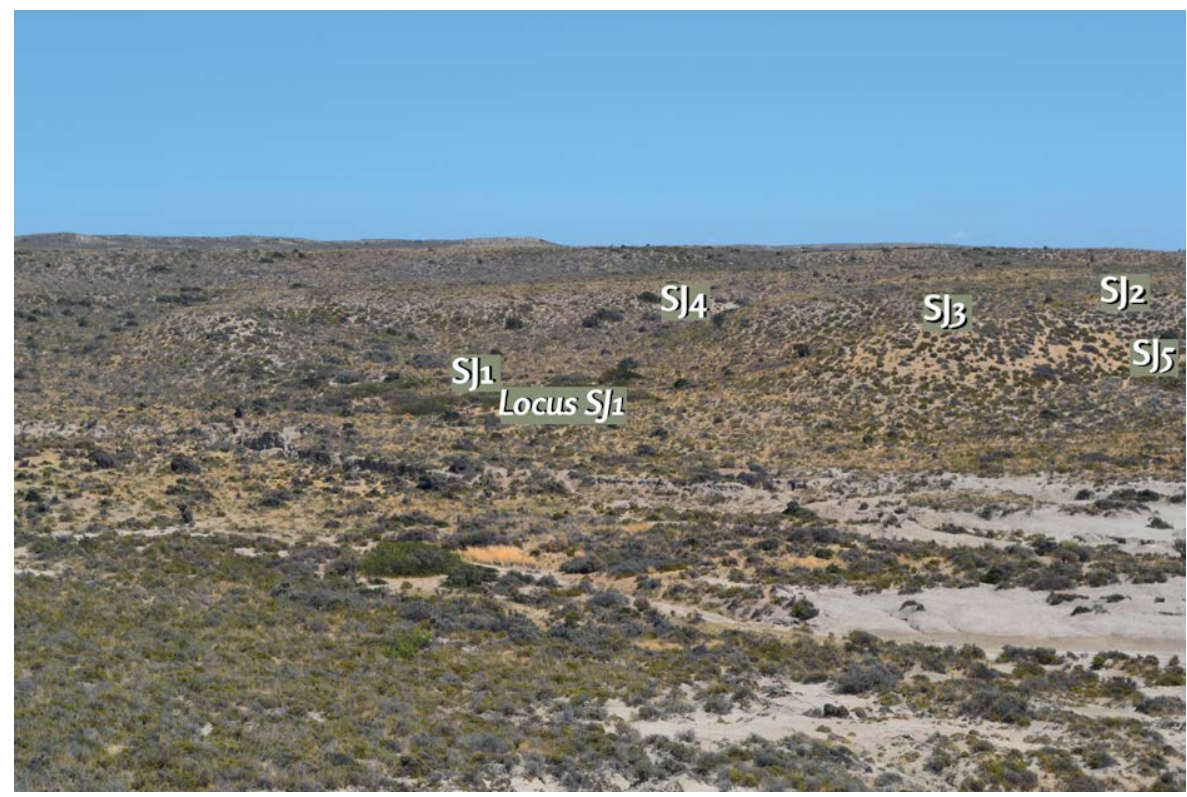

Figura 3. Vista sudoeste del sitio. Se marcan los sectores arqueológicos S/1 a SJ5 (SJ6 está fuera de la foto). En la parte inferior de la foto se puede observar el cañadón y su proximidad al sitio. Hacia la derecha de la foto se ubica la playa.

acumulación en superficie y re exposición de materiales arqueológicos. San José 6 (SJ6) es una acumulación superficial de materiales re depositados por el avance de una cárcava, incluye una concentración de materiales cercana a la playa y un conchero expuesto por un cañadón. Por último, se identificaron dos estructuras modernas, un pozo de agua revestido con ladrillos y cemento y una platea con cimientos modernos (estos últimos, quedan afuera de la foto de la Figura 3).

A continuación, presentamos el abordaje metodológico para cada sector y los resultados obtenidos (Figuras 4 y 5 ).

\section{Sector San José 1}

Este sector corresponde al lugar donde hipotéticamente se habría establecido el núcleo poblacional (Soler y García, 1779) y es una depresión que se forma entre los cerritos, destacándose por su ubicación protegida y central, con vista hacia la playa y por la presencia de un manchón particular de vegetación conformado por jarilla - Larrea divaricata. Éste se distribuye en forma cuadrangular, abarcando una superficie de aproximadamente $256 \mathrm{~m}^{2}$ que contrasta con la baja cobertura vegetal circundante (mayormente piquillín -Condalia microphylla-, quilembay -Chuquiraga avellanedae - y molle -Schinus johnstonii-) (Figura 6I). A partir del mismo, buscamos establecer su relación con cambios específicos del suelo - como presencia de paredes de adobe $o$ acumulaciones de materiales $-y$, por último, la presencia de material colonial en superficie. Para esto, se combinaron distintas estrategias: detector de metales, sondeos para comparar la cobertura vegetal, mapeo de cárcavas, variabilidad en la presencia de materiales en superficie y sub-superficie y la evaluación de las modificaciones culturales en la estratigrafía general de área (Figura 4 A-E).

Con el fin de evaluar la distribución de material de superficie se mapearon por un lado sectores con exposición de materiales arqueológicos y por otro, se diseñó un relevamiento de superficie sobre una línea de $100 \mathrm{~m}$ de longitud, con orientación 


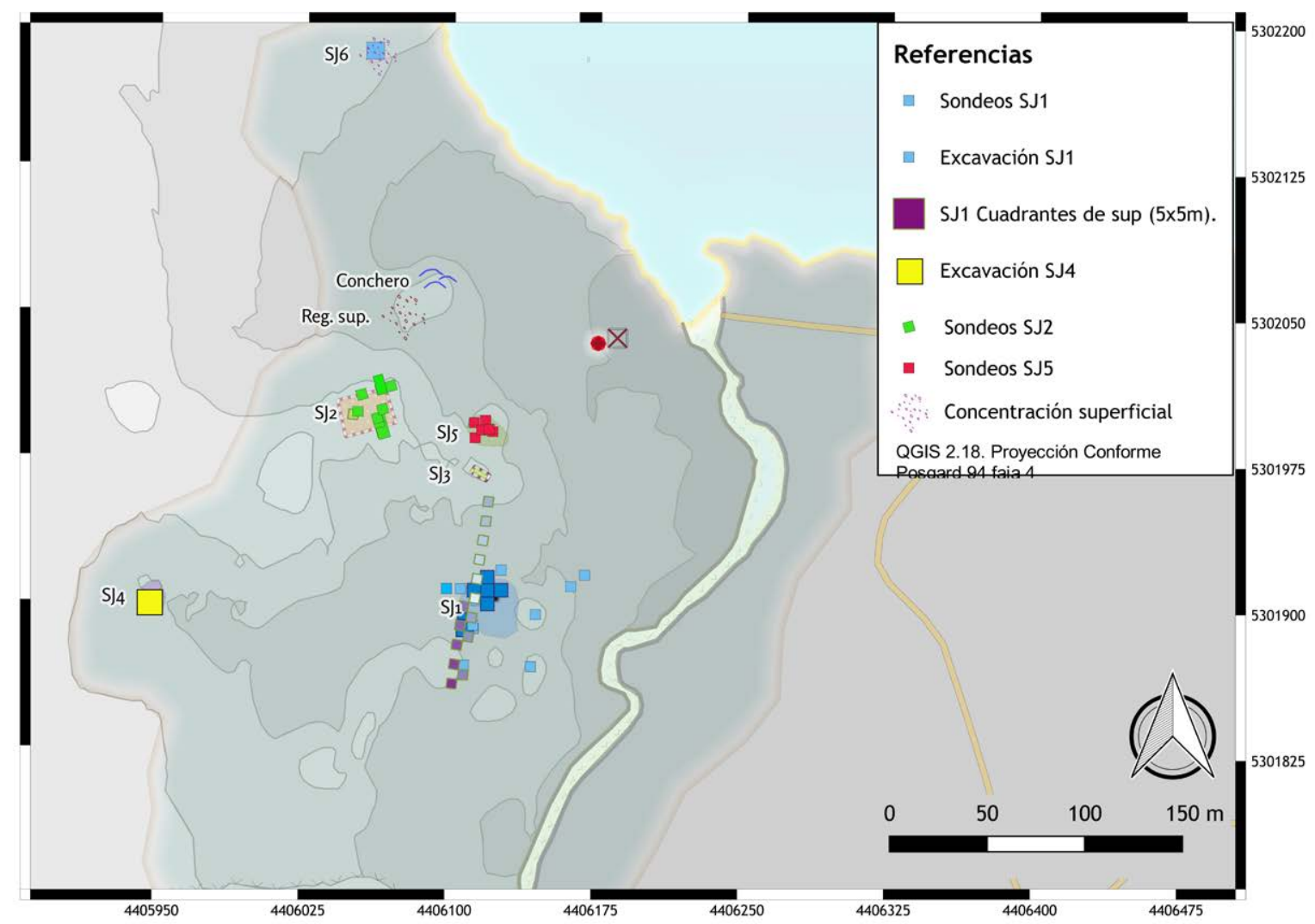

Figura 4. Mapa del sitio arqueológico Fuerte San José. Se detallan las distintas estrategias metodológicas implementadas para abordar los registros de superficie y subsuperficie, todos los sectores (1:3.600).

Norte-Sur en función de las pendientes - acción de la gravedad sumada a la erosión eólica e hídrica-. A ambos lados de ésta, se plantearon 14 cuadrantes de recolección de materiales en superficie de $5 \times 5 \mathrm{~m}$, alternados cada $5 \mathrm{~m}$ a ambos lados de la transecta, desde la ladera sur de SJ3 atravesando todo el sector de SJ1 (Figuras 5A y 7J). En cada uno de los cuadrantes se mapeó la presencia de cárcavas, la pendiente y la cobertura vegetal - la cual se caracterizó ad hoc con una escala ordinal de cero a tres, siendo cero $=$ ausencia de vegetación y tres = cobertura total. La variación altitudinal fue relevada con GPS y nivel óptico y se recolectó la totalidad de los materiales en superficie.

Dicho relevamiento mostró una alta concentración (Relevamiento 1), específicamente en la zona más baja coincidente con baja cobertura vegetal y correlacionada con una mayor abundancia de materiales arqueológicos a nivel subsuperficial (Sondeo g). Los cuadrantes situados a mayor altura, con pendiente pronunciada y menor cobertura vegetal - sobre la ladera sur de SJ3 - también presentan materiales pero en menor magnitud. Así, la pendiente no resulta excluyente para la concentración de materiales en superficie ni para la mayor cobertura vegetal.

Las excavaciones fueron inicialmente ubicadas en la zona más baja y vegetada de SJ1, ya que la cobertura vegetal diferencial podría estar funcionando como un indicador de estructuras sub-superficiales por la sedimentación diferencial y con mayores expectativas de preservación. Sobre la base de un esquema comparativo para evaluar la variabilidad arqueológica en distintos puntos del sector, se realizó una excavación en área de $6 \mathrm{~m}^{2}$, nueve sondeos de $0,5 \mathrm{~m}^{2}$ y uno de $1 \mathrm{~m}^{2}$-campañas 2010 y 2014 - (ver Figura $5 \mathrm{~A}$ ). Estos permitieron delimitar un área con un comportamiento diferencial en 

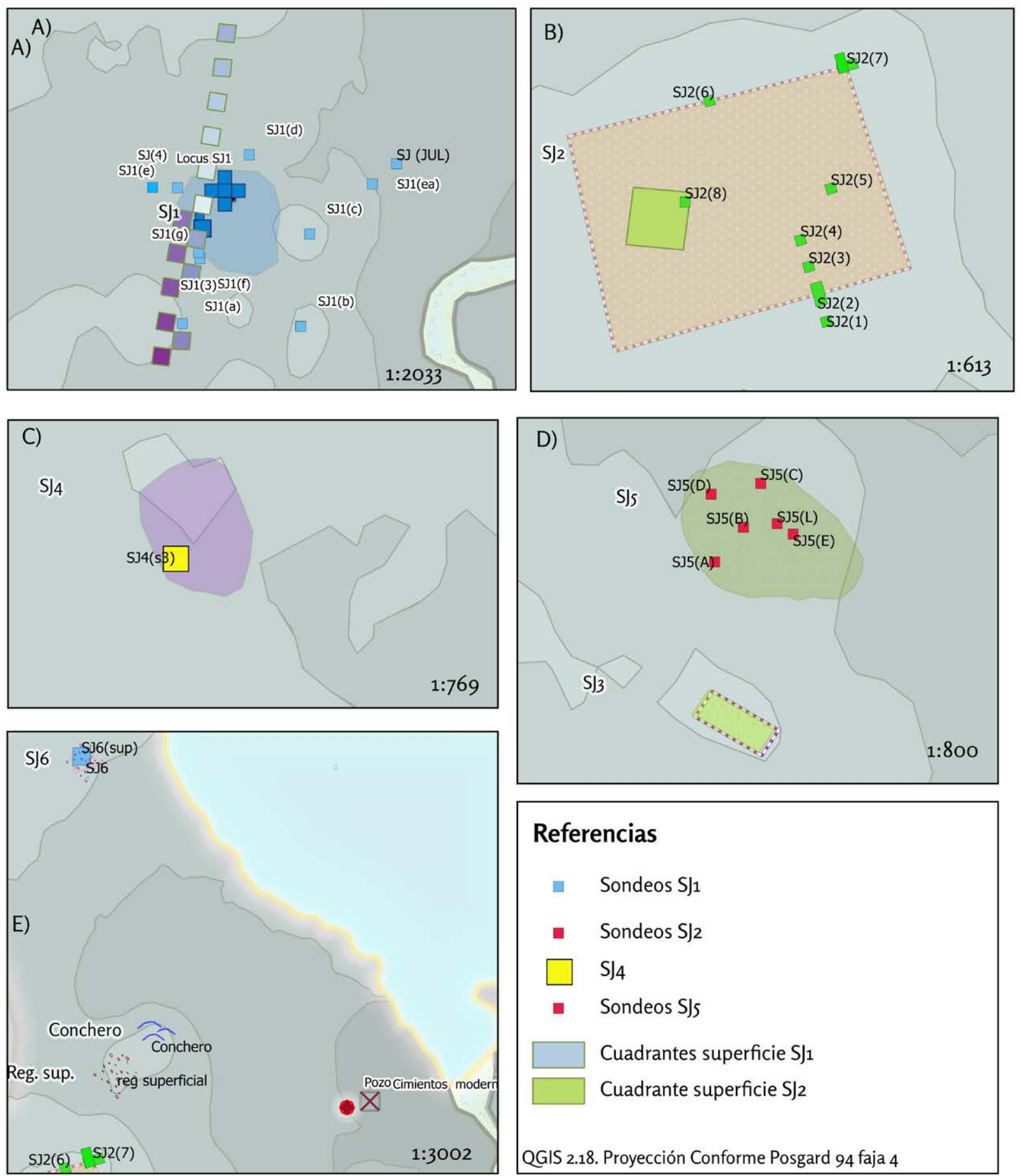

\section{Referencias}

- Sondeos SJ1

- Sondeos Sj2

$\square \quad \mathrm{SJ}_{4}$

- Sondeos S5s

\section{Cuadrantes superficie SJ1}

\section{Cuadrante superficie SJ2}

QGIS 2.18. Proyección Conforme Posgard 94 faja 4

Figura 5. Detalle por sector de las distintas estrategias metodológicas. A) SJ1: cuadrantes de superficie de $5 \times 5 \mathrm{~m}$, sondeos y locus SJ1 (1:2.033); B) SJ2: zanja perimetral, cuadrante de superficie de $5 \times 5 \mathrm{~m}$, sondeos 1 al 8 (1:613); C) SJ4: zona relevada y excavación (1:769); D) SJ3: delimitación estructura de adobe; SJ5: sondeos y zona con materiales en superficie (1:80o); E) SJ6: concentraciones de superficie de la playa y estructuras modernas (1:3.002).

función de la distribución espacial acotada de un depósito limo arenoso con materiales coloniales en contraste con la estratigrafía natural del área (Figura 7H).

En dicho sector se identificaron cuatro niveles estratigráficos cuyo análisis sedimentológico está en proceso: 1) "superior", de origen eólico, arenoso y muy 


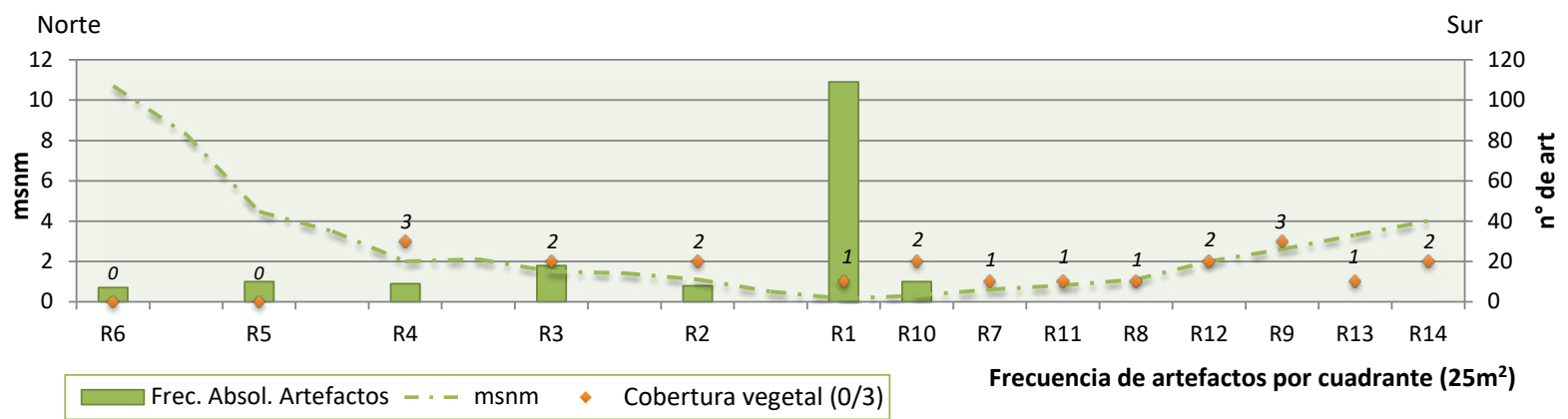

Figura 6. Gráfico compuesto: frecuencia absoluta de artefactos por cuadrante de superficie (25 m2) y variación altitudinal (m s.n.m.), ambos en escala. Los puntos naranjas indican una escala ordinal (o/3) de cobertura vegetal. Los cuadrantes sin referencia no fueron relevados.

perturbado por acción de las raíces, con materiales coloniales y modernos con una potencia aproximada $0,05 \mathrm{~m} ; 2$ ) "arenoso", muy homogéneo y húmedo, correspondiente posiblemente a un episodio de formación de una pequeña duna, potencia aproximada $0,08 \mathrm{~m} ; 3)$ "gris compacto", limo-arenoso de coloración grisácea, con evidencias de intensa actividad de animales cavadores con baja presencia de micro fragmentos de valvas trituradas y materiales asociados exclusivamente a una cronología de fines del siglo XVIII, siendo su potencia aproximada $0,03 \mathrm{~m}$; y 4) "arena consolidada", depósito del Terciario compactado y muy homogéneo, estéril arqueológicamente (Buscaglia et al., 2012). Es importante mencionar que la potencia total fue menor a $0,2 \mathrm{~m}$, con una representación y distribución variable de materiales arqueológicos (Figura 7 A-G).

En función de definir la distribución del depósito gris compacto en sub-superficie y avanzar sobre los posibles agentes antrópicos y naturales - principalmente erosivosrelacionados con su formación, se realizaron siete sondeos, cuya localización contempló: presencia/ausencia de vegetación, de montículos y de materiales en superficie.

Los sondeos - a, b, c, d, f y 3 - mostraron en su mayoría la estratigrafía natural y fueron estériles arqueológicamente, con excepción de los sondeos (e) y (g), que presentaron un comportamiento similar a la excavación de 2010 - locus SJ1. Estos tres últimos loci, presentaron diferencias a nivel de la superficie - la excavación se ubicó en la zona más baja y con mayor densidad de vegetación, mientras que los sondeos se ubicaron hacia el Oeste en zonas más altas, con pendiente al Este y de menor cobertura vegetal. Sin embargo, fueron similares en sus someras estratigrafías y materiales arqueológicos. Es importante señalar que, de todos los sectores investigados, el sector SJ1 es el que ha presentado una mayor abundancia y diversidad de restos materiales asignables a la ocupación española, tanto en superficie como en estratigrafía (Figura 7A-G).

Con respecto al registro arqueofaunístico, el estado de preservación general de los especímenes es bueno, particularmente el registro de subsuperficie. La identificabilidad fue alta, ya que de los 2.259 especímenes recuperados un 83,6\% fueron identificados a nivel de clase u orden (62,1\% a nivel de familia o especie), en tanto que los restantes resultaron indeterminados. La diversidad está representada principalmente por restos de mamíferos (i.e. indeterminados, Ovis sp., Artiodactyla, Zaedyus pichii, Lama guanicoe, Bos taurus, Equus ferus y Rodentia), moluscos y aves (Figura 7F). En el nivel gris compacto predominan los mamíferos, aunque debido al nivel de fragmentación en su mayoría no han podido clasificarse a nivel de familia o especie. Tanto en excavación como en superficie, se observa un predominio de especímenes pequeños (menos de $2 \mathrm{~cm}$ ), de los cuales un 55,5\% corresponden a fragmentos de valvas, que en su mayor parte $(87,7 \%)$ proceden de un conchero con evidencias de huaqueo (Sondeo 4 ). 

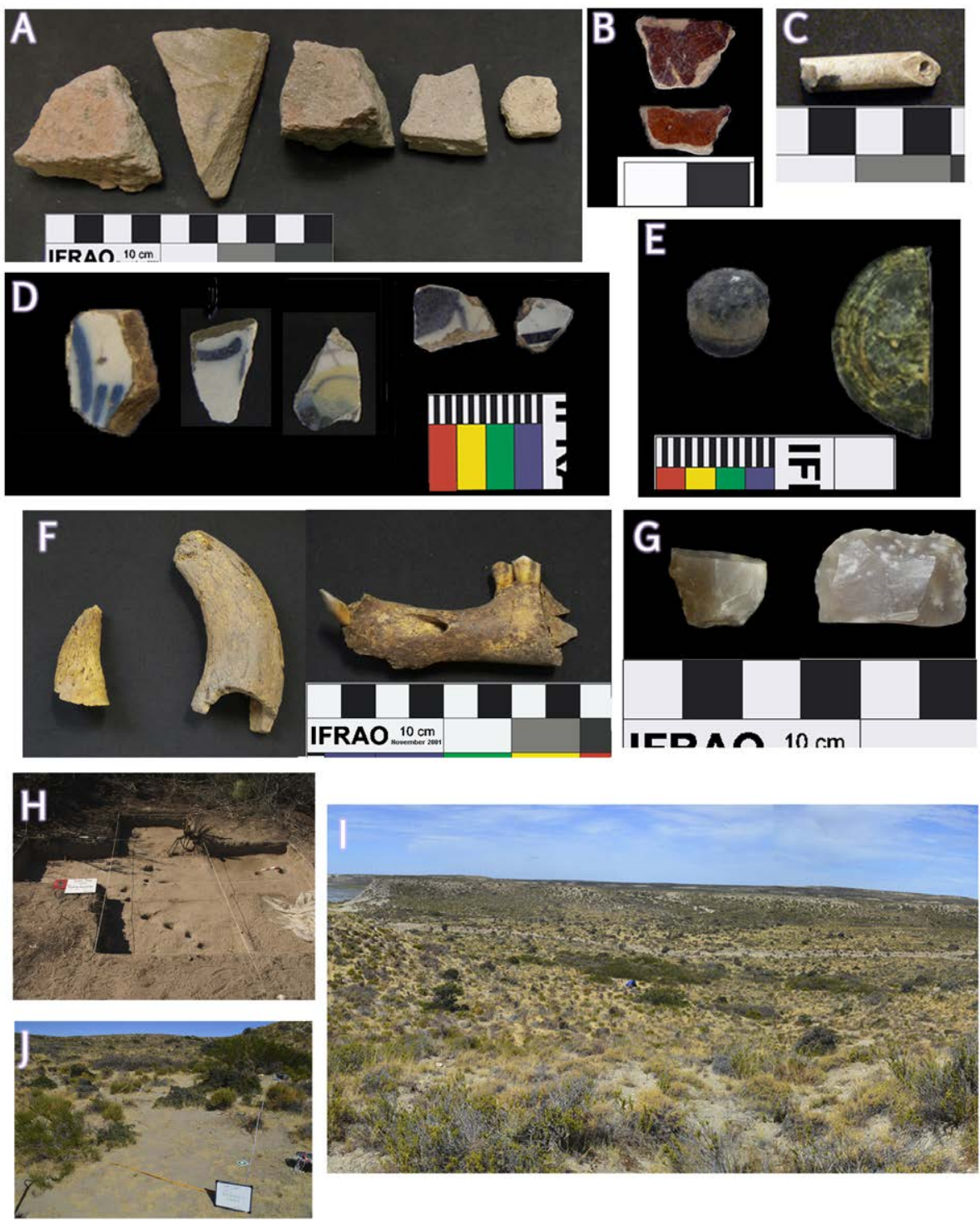

Figura 7. Materiales arqueológicos de SJ1. A) fragmentos de contenedores - botijas-; B) fragmentos de cerámica roja vidriada; $C$ ) fragmento de caña de pipa de caolín; $D$ ) fragmentos de cerámica doméstica - mayólica-; E) izquierda, munición de plomo y derecha, botón de uniforme de la Armada española del siglo XVIII; F) izquierda, fragmentos de proceso cornual de Bos taurus y derecha, mandíbula Lama guanicoe; $G$ ) chisperos franceses en calcedonia; $H$ ) excavación del locus SJ1, se observan los pozos de animales cavadores; I) vista Este de $S_{1}$; J) detalle del terreno en los relevamientos de superficie.

Se registró una baja frecuencia (alrededor de 7\%) de marcas y fracturas de origen antrópico en los especímenes para los tres niveles estratigráficos, mientras que en superficie no se han registrado. Acordes a las tendencias observadas, los especímenes asignados a Ovis sp. presentan la mayor cantidad de modificaciones antrópicas seguidos de los indeterminados. En cuanto a las evidencias de termoalteración, en la muestra arqueofaunística predominan los especímenes no quemados por encima del $90 \%$.

Si bien la meteorización es heterogénea, se observan condiciones de relativa estabilidad de los depósitos, aunque el nivel gris compacto presenta evidencia de permanencia sobre la superficie - estadio $2(35,8 \%) ; 3(28,5 \%)$ y $4(21,2 \%)$. En contraposición, el estadio 1 predomina en niveles superior $(23,2 \%)$ y arenoso $(37,2 \%)$. Ello se ve reflejado en los especímenes de Ovis sp., con predominio de elementos completos y articulados del esqueleto apendicular — tercera articulación-, resultado de acciones 
de trozamiento primario, posiblemente luego de la ocupación colonial (Buscaglia et al., 2012).

Desde el punto de vista de la acción de agentes tafonómicos, los conjuntos presentarían integridad alta, dada la baja incidencia de agentes, roedores y carnívoros en la totalidad de la muestra ósea ( $88,7 \%$ no presentan marcas de ningún tipo), siendo prácticamente nula la acción de carnívoros y roedores en el nivel gris compacto. Sin embargo, se observó el deterioro del registro óseo por acción de las raíces y la humedad, especialmente donde se realizaron las excavaciones en el año 2010, caracterizada como un área deprimida y con alta cobertura vegetal. La acción de la humedad se evidencia en los tres niveles, donde un 19,4\% de los especímenes presentan tinción por manganeso y hongos, concentrándose su incidencia en el nivel arenoso, seguido del superior y por último el gris compacto.

Con respecto a la cerámica, esta fue hallada tanto en superficie como en subsuperficie, destacándose en ambos casos su concentración en la zona de la excavación, llegando en todas las cuadrículas y sondeos a un $71 \%$-y un $85 \%$ si agregamos el cuadrante de recolección superficial de $25 \mathrm{~m}^{2}$ que se superpone en área. Entre las cuadrículas del locus SJ1 el volumen excavado es similar $\left(0,20 \mathrm{~m}^{3}\right)$ así como la diversidad de categorías funcionales de cerámica - almacenamiento/transporte, doméstica, construcción, otros e indeterminadas. En las cuadrículas predominan los restos de lozas para el servicio de mesa - creamware y mayólica - , de cerámica roja — para cocción y servir- y de botijas - contendores - manteniendo un 10-15\% de indeterminados (Figura 7A-D). Se destaca el cuadrante de superficie R1 con una alta representación de restos de ladrillos que no se reitera en otros sectores superficiales - aunque sí en el Sondeo 4.

Con relación a las variables postdepostacionales, la muestra de cerámica presenta un 93\% de fractura angular, con ausencia de redondeamiento, quemado y líquenes. La ausencia de redondenamiento en las fracturas es interesante a la hora de examinar las evidencias de migración vertical por acción de las escorrentías y fuertes lluvias. Con respecto a los módulos de tamaño, un 65\% de la muestra es menor a $2 \mathrm{~cm}^{2}$, al tiempo que el $95 \%$ presenta tamaños menores a $10 \mathrm{~cm}^{2}$. Con relación a la identificación funcional, solamente hay fragmentos mayores a $15 \mathrm{~cm}^{2}$ en restos de contenedor y ladrillos. Por último, dentro de los indeterminados, el $83 \%$ es menor a $2 \mathrm{~cm}^{2}$, dando cuenta de su baja identificabilidad.

Si sumamos los restos vítreos - sólo el 3\% del total en el caso de SJ1 - se reitera la concentración en el nivel superior del locus SJ1 (79,6\%), con menor representación en los cuadrantes de superficie. Se destaca la deshidratación por exposición solar para el nivel gris compacto (80\%), resultando a su vez, en una baja identificabilidad. Al igual que la cerámica, no se observa redondeamiento, pulido y/o quemado, y un $84 \%$ de la muestra es menor a $10 \mathrm{~cm}^{2}$. Dado el estado de la misma, no es posible una asignación cronológica fehaciente.

Con respecto a los metales, en su mayoría se han encontrado en muy mal estado de conservación, muy fragmentados y con alto nivel de oxidación — sin persistencia de núcleo metálico y pérdida de morfología superficial-, que resulta en casi un $70 \%$ de indeterminados. De los 300 fragmentos recuperados en SJ1, el 31\% son restos de clavos no identificables macroscópicamente. Esto se relaciona posiblemente con las características del sedimento, la alta salinidad y la presencia de vegetación que retiene la humedad (Bernard y Joiret, 2009; Gerwin y Baumhauer, 2000). Del conjunto, se destaca la presencia de un botón de la Armada española del siglo XVIII en el nivel gris compacto y una munición de plomo en el nivel arenoso en el locus SJ1 (Figura 7E).

En el caso de los artefactos líticos, como se observa en la Tabla 1, corresponden a la categoría con menor representación en la muestra arqueológica recuperada en SJ1, 
aunque hasta al momento no se ha podido corroborar su relación con la ocupación colonial. Sin embargo, el registro lítico se concentra mayormente en el locus SJ1 $(\mathrm{n}=6)$ y en el Sondeo (ea) $(n=5)$ realizado en el 2014, seguidos de los cuadrantes de superficie $(n=4)$. Predominan las lascas $(n=5)$, guijarros $(n=3)$, chunks $(n=3)$, chisperos $(n=2)$, raspadores $(n=1)$ y desechos indiferenciados $(n=1)$. Con respecto a los chisperos, cabe señalar su importancia como marcadores cronológicos. Uno de ellos fue recuperado en el nivel gris compacto de la cuadrícula B0 y el segundo en la superficie del S (ea). Por sus características tecnotipológicas y materia prima - calcedonia - se corroboró un origen francés de fines del siglo XVIII para ambos (Buscaglia, Alberti y Álvarez, 2016) (Figura $7 \mathrm{G})$. Desde el punto de vista de la acción de agentes postdepositacionales, no hemos registrado evidencias de termoalteración, líquenes, pátinas, ventifacción, entre otros.

De acuerdo a la información sobre los procesos postdepositacionales, observamos que la acción de la gravedad por la pendiente, acción hídrica y eólica, no habría influenciado las concentraciones de materiales, aunque no descartamos su incidencia. Asimismo, los depósitos serían relativamente estables y con una integridad alta; aunque la acción de raíces, animales cavadores y una matriz predominantemente arenosa posiblemente incidan en la migración de los artefactos, sobre todo aquellos de tamaños más pequeños registrados en los niveles cercanos a la superficie. La preservación de los materiales es diferencial de acuerdo a su composición, siendo los metales la categoría más afectada por las condiciones ambientales. Prácticamente no se observaron evidencias de termoalteración en el conjunto artefactual, lo cual abre un interrogante respecto al incendio mencionado en las fuentes históricas cuando el asentamiento fue atacado por indígenas en 1810 (Aragón, 1810). Finalmente, la ausencia de materiales arqueológicos de tamaños mayores, enteros y vistosos, nos alerta también sobre las actividades antrópicas en este sector, relacionadas con la recolección y reclamación a lo largo del tiempo, tal como fue presentado en la introducción.

\section{Sector San José 2}

Se trata de la única estructura que puede ser correlacionada directamente con lo mencionado en las fuentes históricas, tal como se describe en el informe de Soler y García (1779) y el diario de la expedición de Libanus Jones cuando reocupan el Fuerte San José en 1812 (Jones 1855 en Dumrauf, 1991). SJ2 se encuentra situada sobre uno de los cerros y cuenta con una ubicación estratégica en términos de su visibilidad hacia el golfo San José y la estepa hacia el sur/sudoeste de la península, aunque esta ubicación la deja también expuesta a fuertes vientos (Figuras $5 \mathrm{~B}$ y $8 \mathrm{~F}$ ). Uno de los rasgos principales que caracteriza a esta estructura está dado por la presencia de una zanja cuasi perimetral de 17 x $20 \mathrm{~m}$, claramente visible en superficie, así como la presencia de montículos internos, que presentan dos grandes pozos en su interior (Figura 8E), registrándose en superficie materiales arqueológicos de fines del siglo XVIII (Figura 8D y G).

En el sector SJ2 se realizaron relevamientos topográficos, planimétricos, recolecciones de material de superficie y ocho sondeos de dimensiones variables con el objeto de evaluar los rasgos - zanja, pozos y montículos - así como el comportamiento del registro arqueológico (Figura 5B).

La recolección de materiales arqueológicos en superficie fue realizada mediante un cuadrante de 4 x $4 \mathrm{~m}$ ubicado en el interior de SJ2. Si bien la recolección tuvo como objetivo principal obtener una muestra de superficie de manera sistemática y pasible de ser comparada con otros sectores, se buscó también asegurar la preservación de materiales sujetos a intensos procesos erosivos debido a su exposición sobre la cima del cerro y a la recolección ilegal por actividades de huaqueo. Como resultado, la recolección arrojó una baja frecuencia de materiales arqueológicos $(\mathrm{n}=30)$, conformada 

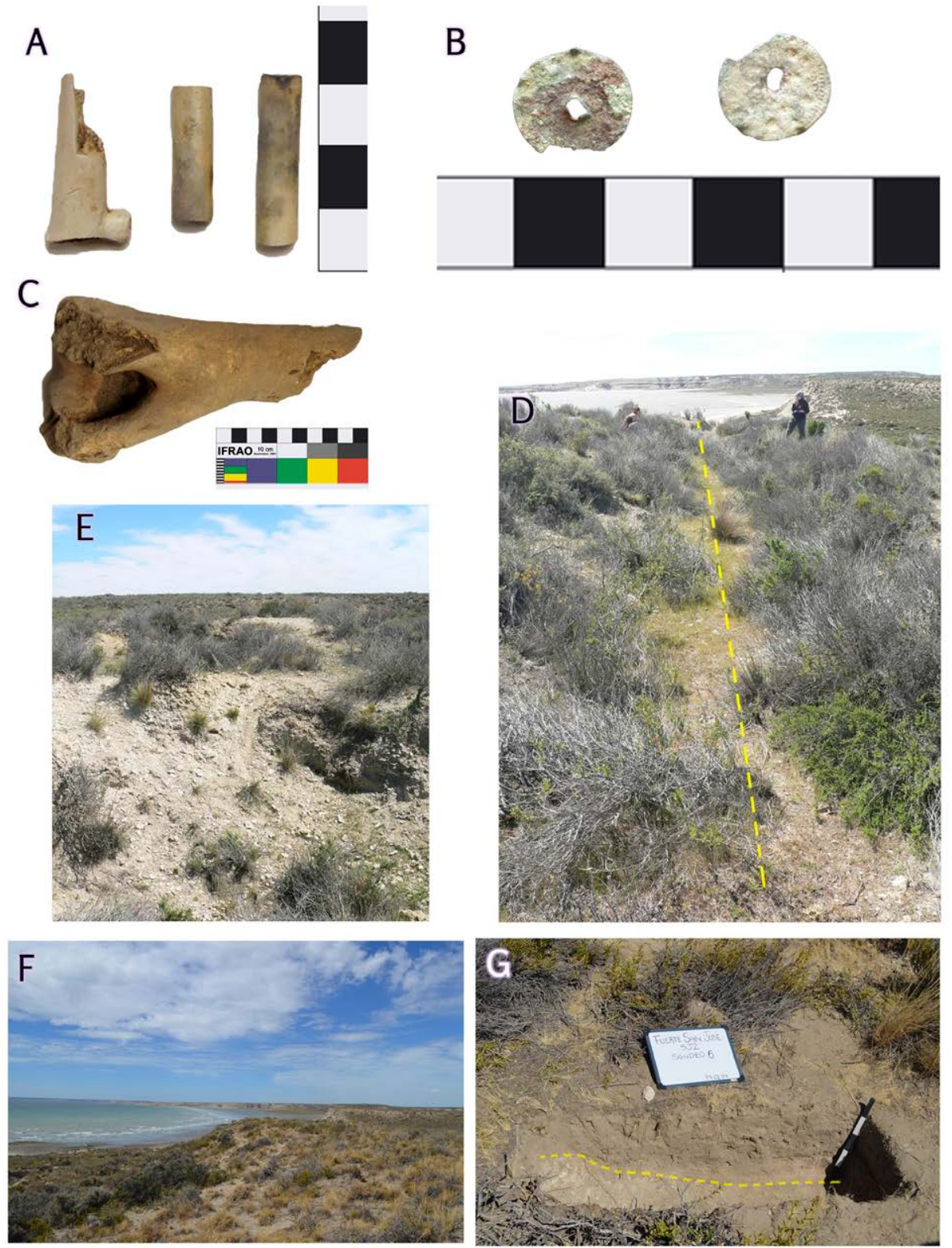

Figura 8. Materiales arqueológicos de SJ2. A) pipas de caolín -talón y caña-; B) jeton -anverso y reverso; C) fragmento de fémur de Bos Taurus; D) vista del sector, se señala la zanja perimetral; $E$ ) pozo excavado en SJ2; F) vista Noreste del golfo desde SJ2; G) sondeo 6, se señala la cubeta de la zanja excavada arqueológicamente.

principalmente por restos de cerámica (fragmentos de ladrillos, de pipas de caolín y de vajilla doméstica), metal (en su mayor parte clavos de hierro de cuerpo de sección cuadrada, un jetón del siglo XVIII —Figura 8B-, alambres e indeterminados) y vidrio (un fragmento de vidrio plano incoloro) - ver Tabla 1 y Figuras $8 \mathrm{~A}$ y C. En general los materiales arqueológicos presentaron signos de alteraciones postdepositacionales, consistentes mayormente en erosión, abradido y en algunos casos como la cerámica, quemado.

Dado que uno de los objetivos de las investigaciones fue evaluar el origen y el comportamiento de la zanja perimetral, nos detendremos en la descripción de los sondeos ubicados en los lados sur -1 a $3-$ y norte -6 y 7 - Los restantes sondeos $-4,5$ y 8 - evaluaron distintos sectores intermedios al interior de SJ2, resultando 
estériles arqueológicamente. Se observaron pequeñas diferencias en ambos lados de la zanja: el lado sur se caracterizó por una matriz arenosa con conchillas enteras fósiles, cuyo nivel de fragmentación aumenta con la profundidad hasta una transición de arena rojiza sin valvas. Luego se observa la base de la cubeta excavada intencionalmente en un nivel de valvas fósiles no consolidadas del terciario, con una potencia de 0,54 $\mathrm{m}$. Sólo se registraron tres especímenes de mamíferos pequeños indeterminados en estadios 2 y 3 de meteorización, así como un fragmento de ladrillo sobre el final de la excavación. El lado norte se caracterizó por una matriz sedimentaria arenosa, suelta y con muy pocas valvas fósiles fragmentadas. A mayor profundidad la matriz se vuelve muy homogénea, arcillosa y compacta, a diferencia de lo observado en el lado sur. Sin embargo, también se registró el mismo comportamiento en la base de la cubeta, alcanzando una potencia máxima de $0,5 \mathrm{~m}$. Se recuperaron tan solo dos fragmentos de fémur de bóvido - estadio 2 de meteorización-, uno de ellos con marcas antrópicas (Figura 8C) y dispuesto junto a una lente de carbones, interpretada como restos de una estructura de combustión.

\section{Sector San José 3}

Se encuentra situado en el extremo Noreste del cerro, caracterizado por una muy baja cobertura vegetal y una oquedad de forma rectangular de 3 x 1,5 m excavada sobre la roca madre (Figuras 3, 5D y 9B). Cabe destacar la presencia de manchones de adobe erosionado y quemado sobre sus bordes y paredes.

El relevamiento tuvo por objeto entonces demarcar el perímetro y la forma de la mancha circundante al pozo y evaluar la presencia de adobe. Para ello se procedió a efectuar una limpieza perimetral, delimitándose una línea de cimientos de $6,15 \times 4,3 \mathrm{~m}$, claramente definida en los lados norte, este y sur. El lado sur, mejor definido, mostró un rastro de pared de adobe con evidencias de termoalteración de 0,6 $\mathrm{m}$ de ancho, siguiendo la orientación del promontorio rocoso (Figura 9A y C). No se hallaron materiales arqueológicos, lo que no es llamativo dada la exposición de su localización.

\section{Sector San José 4}

Se trata de un nuevo sector identificado en el año 2014 que corresponde al área donde a mediados de la década de 1980 cuatro individuos fueron exhumados por aficionados. Este sector se caracteriza por estar ubicado en una zona alta en una herradura entre dos cerros, a $150 \mathrm{~m}$ al Oeste y por encima del sector SJ1 (Figuras 2 y 3). Se trata de una zona propicia para la formación de médanos y representa un área crítica en relación con la exposición a procesos erosivos tanto eólicos como hídricos por la formación activa de escorrentías, cárcavas y cañadones, con una elevada dinámica aún en la actualidad. Si bien la cobertura vegetal es baja, la presencia de coirón y otras especies como molle y calafate contribuye a la fijación de los médanos.

Los trabajos de investigación estuvieron dirigidos a corroborar sí se trataba de un área con enterratorios humanos y a evaluar el impacto de las excavaciones asistemáticas realizadas por los aficionados (Figura 5C). Sobre la base de estos trabajos se hallaron pequeñas concentraciones de restos óseos muy meteorizados y en avanzado estado de desintegración. Se diferenciaron tres subsectores dentro del sector excavado en la década de 1980 donde se exhumaron restos humanos en un radio de $10 \mathrm{~m}$. En el tercer subsector, sobre un perfil desmoronado producto de la acción erosiva de una cárcava y la presencia de una cueva de roedor, los trabajos de zarandeo permitieron la recuperación de un metatarso correspondiente a un pie humano, en un estado de preservación relativamente bueno. Este hallazgo dio lugar al descubrimiento de 

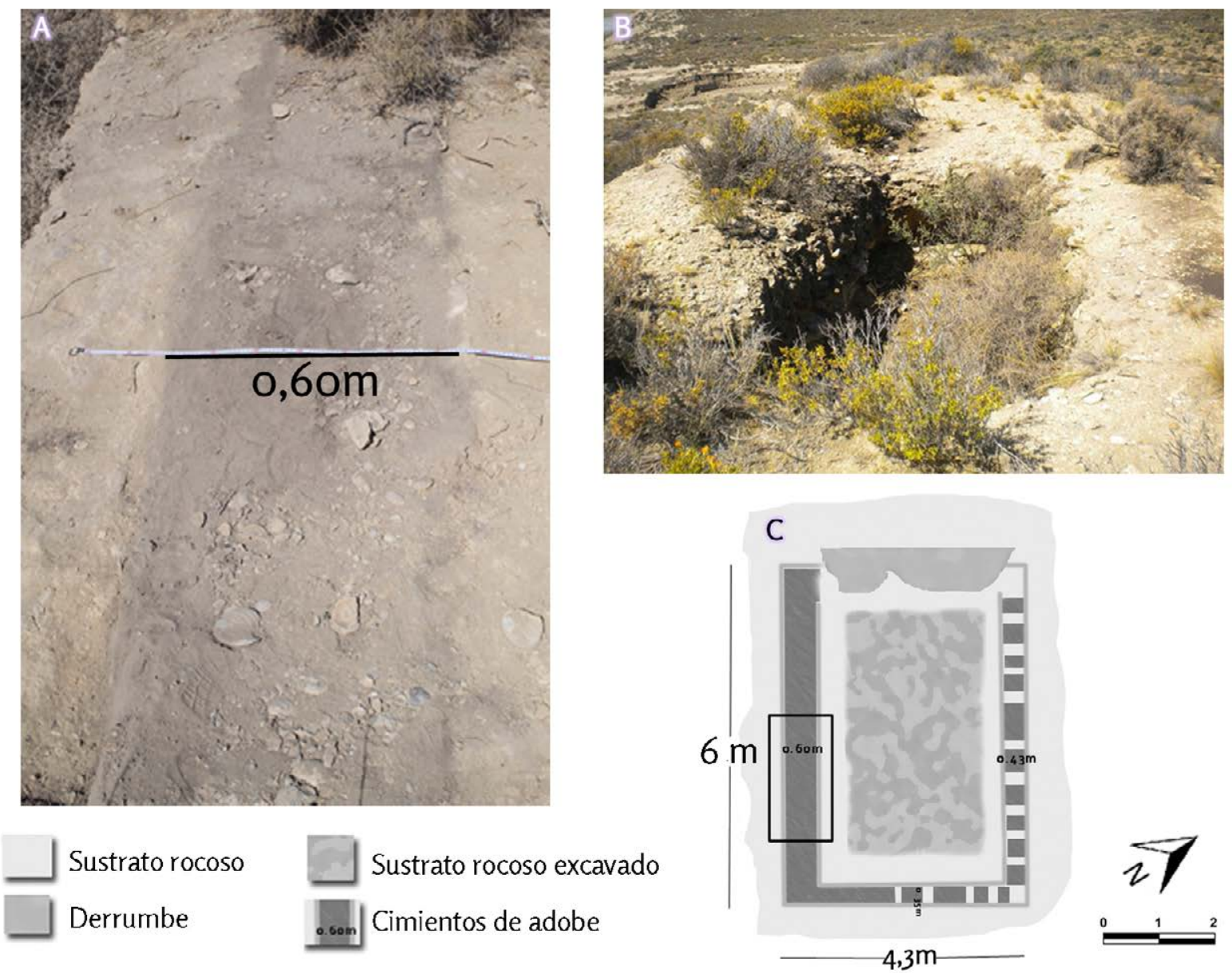

Figura 9. A) foto de la línea de cimientos de adobe; B) vista de SJ3 y del pozo: C) planta de la estructura de SJ3.

un nuevo enterratorio, que fue excavado debido a que se encontraba en proceso de re-exposición inminente y a los riesgos advertidos por un huaqueo reciente del sitio. El abordaje bioarqueológico permitió adscribir al individuo a la población del Fuerte San José (para más información ver García Guráieb et al., 2017).

\section{Sector San José 5}

Las investigaciones arqueológicas en la ladera norte que da a la playa, sobre el cerro norte estuvieron dirigidas a evaluar el comportamiento del registro arqueológico sobre la pendiente situada por debajo de la estructura SJ3 (Figuras 3 y 5D). Se trata de una acumulación de materiales de superficie sobre la pendiente de carácter longitudinal, cuyo origen podría estar relacionado con el descarte, re-exposición y re-depositación de restos materiales en función de la intervención de distintos agentes, tanto naturales como culturales (Figura $10 \mathrm{~K}$ y L). De manera similar a otros sectores del sitio arqueológico, en SJ5 también se registraron actividades de huaqueo en las distintas campañas que realizamos.

En función de la distribución del registro arqueológico, se plantearon tres sondeos de $0,5 \mathrm{~m}^{2}-\mathrm{A}, \mathrm{B}$ y $\mathrm{C}$ - sobre una recta de $11,5 \mathrm{~m}$ orientada al Norte, cuyo desnivel alcanza $\operatorname{los} 3 \mathrm{~m}-$ con una pendiente de $17^{\circ}$. En la línea central se planteó otro eje perpendicular con dos sondeos en cruz - D y E. En todos los casos, los sondeos se distanciaron 5 
A

A
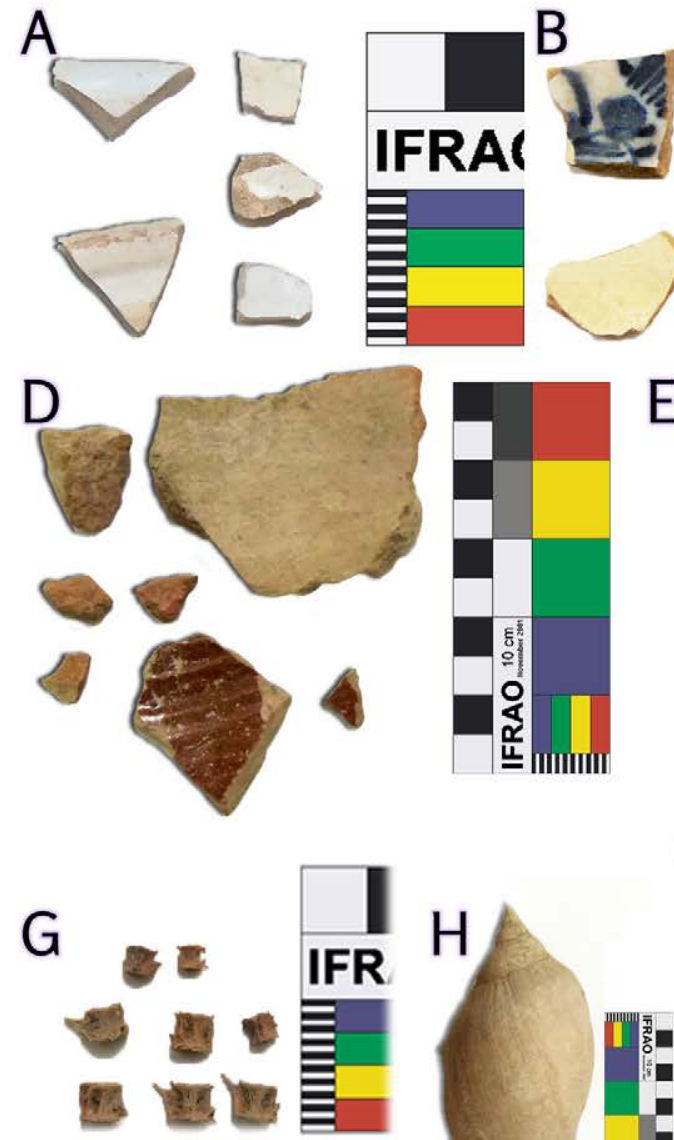

I

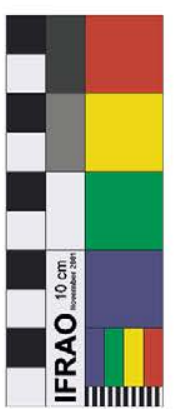

$\mathrm{E}$
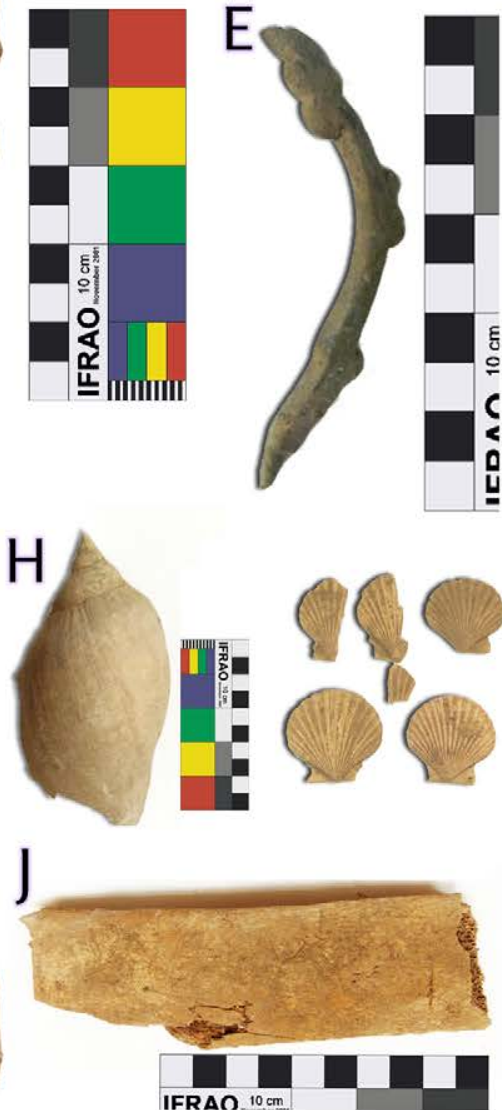

IFRAO $10 \mathrm{~cm}$

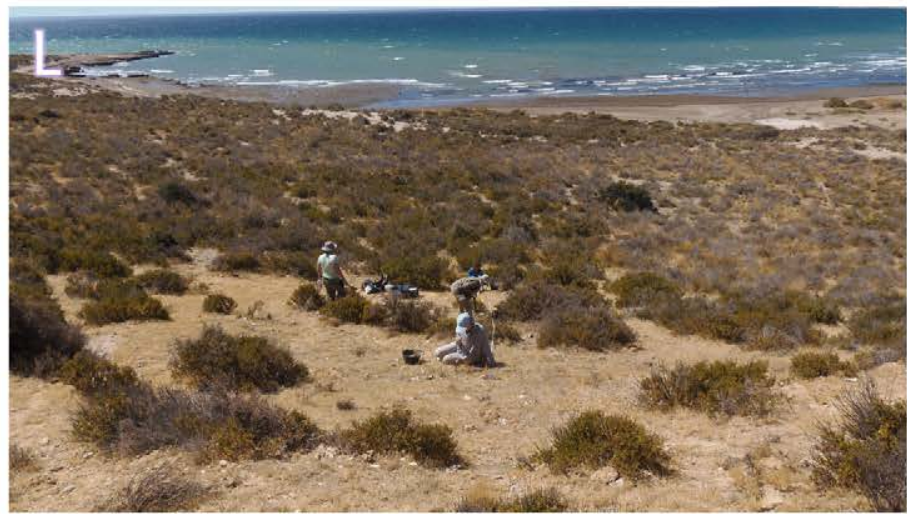

C
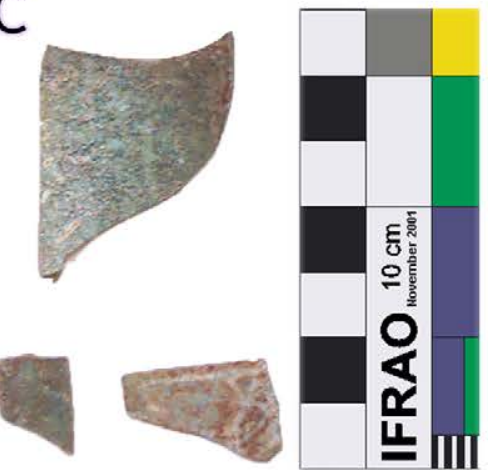

$\mathrm{F}$
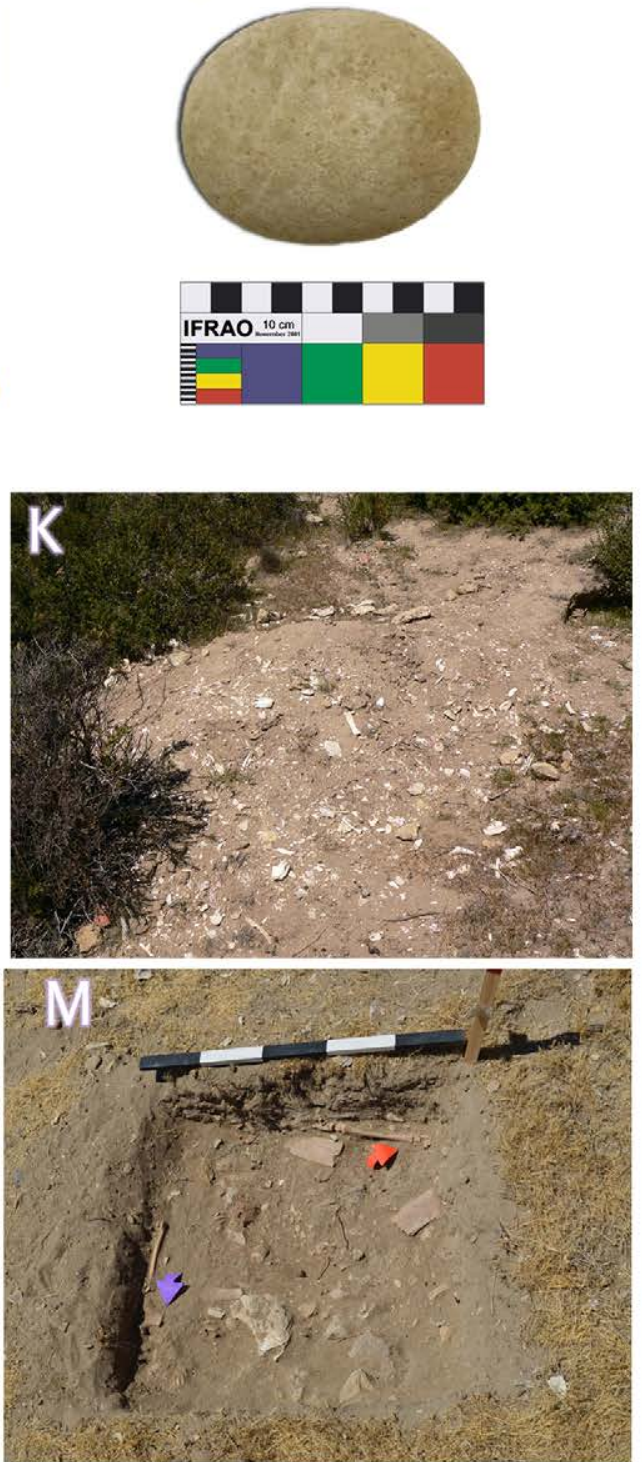

Figura 10. Materiales arqueológicos de SJ5. A) cerámica doméstica -mayólica lisa-; B) cerámica doméstica -mayólica azul sobre blanco y loza creamware-; C) fragmentos de vidrio de botella cuadrada de ginebra, se observa el grado de deshidratación; D) arriba, fragmentos de contenedores - botijas - y fragmentos de cerámica doméstica - vidriada roja-; E) fragmento de asa de bronce decorada; $F$ ) percutor en roca sedimentaria; G) vértebras de Eliginops maclovinus; $H$ ) izquierda, gasterópodo de fondo oceánico y derecha, Chlamys tehuelchus; I) vértebra de cetáceo; J) costilla de Bos taurus, con marcas de corte y trozamiento estandarizado; K) vista de SJ5, área de descarte secundaria; $L)$ vista sur de SJs y el golfo al fondo; M) sondeo D, se observa la abundancia de materiales en planta. 
m entre sí. Se agregó la limpieza de una cueva de roedor —Sondeo L- en la que se observó la re-exposición de una gran cantidad de materiales.

La estratigrafía fue concordante entre todos los sondeos: nivel 1, superior, arcilloarenoso, con restos de ostras fósiles (Ostrea máxima); nivel 2, gris castaño de matriz limo-arenosa con alta presencia de valvas trituradas de Chlamys tehuelchus - vieiras-; y nivel 3, arenoso sin restos malacológicos en la matriz sedimentaria. La potencia de los sondeos varió de 0,50 a $0,70 \mathrm{~m}$ de profundidad. Se verificó presencia de materiales arqueológicos en todos los niveles, variando en su densidad (Figura 10A-J). La pendiente y el rodamiento no parecen ser los factores determinantes de la acumulación, ya que de los 2.253 restos recuperados en SJ5, un 86,7\% se concentran en el sector medio de la pendiente $-\mathrm{y}$ no en la parte inferior- mientras que los sondeos restantes muestran semejanzas en la distribución.

A su vez, la predominancia de los restos arqueofaunísticos y malacológicos (95\%) define un perfil menos diverso que SJ1, en tanto el resto de las categorías de materiales presentan muy baja representación. Se destaca el SD por su mayor abundancia de materiales en todos los niveles (36,5\%), siendo la densidad relativa cuatro veces mayor al resto de los sondeos (Figura 10M). Por otra parte, sí es común a todos los sondeos la mayor frecuencia y diversidad de materiales en el nivel 3. El nivel 2 presenta frecuencias mucho menores y se destacan allí las vieras trituradas.

El estado de preservación de los especímenes arqueofaunísticos recuperados en SJ5 es muy bueno: el $87,3 \%$ son menores a $5 \mathrm{~cm}$. Sin embargo, no se observa una relación clara entre la distribución de los módulos de tamaño y la pendiente - mayor abundancia de especímenes pequeños en los sondeos inferiores. El grado de identificabilidad taxonómica fue alto, ya que de la totalidad especímenes recuperados, un $93,9 \%$ fue identificado a nivel de clase u orden, aunque solo un 30,9\% a nivel de familia o especie. En SJ5 se observa una mayor diversidad a diferencia de SJ1: se destacan los mamíferos, las aves, los restos malacológicos y los peces. Entre los mamíferos predominan los indeterminados - entre los que posiblemente se encuentran pinnípedos-, Zaedyus pichii, Rodentia, Bos taurus, Artiodactyla, Pseudalopex sp., Ovis sp., cetáceos, Sus scrofa (Figura 10I y J). Entre las aves predominan los restos esqueletales y cáscara de Pterocnemia pennata, indeterminados y Gallus gallus. Entre los restos de moluscos, observamos una relativa diversidad representada en primer lugar por Chlamys tehuelchus, Mytilus platensis, Ostreidae, Buccinanops globulosus, Fissurella sp. y volutas, entre otros (Figura 10H). Ello da cuenta del aprovechamiento de una diversidad de moluscos de la franja intermareal. Por último, también se registraron especímenes correspondientes a Chondrichthyes y Osteichtyes, entre los cuales se identificó Bovichthys argentinus y Eliginops maclovinu (Figura 10G).

Es importante destacar que el nivel 3 presenta la mayor abundancia $(69,4 \%)$ y diversidad con relación al resto de los niveles. Dicho nivel se caracteriza por la representación de mamíferos muy grandes y de especímenes correspondientes a taxones de especies europeas -i.e. Bos taurus, Sus scrofa, Gallus gallus. El ganado vacuno y los animales de corral formaron parte de las especies introducidas en la península por los pobladores del Fuerte San José. Entre las especies locales se identificaron: ñandú, mamíferos marinos - pinnípedos y cetáceos (Figura 10I) - , bivalvos, gasterópodos - entre ellos, una especie no identificada de fondo oceánico (Figura $10 \mathrm{H}$ ) -, peces y roedores entre otros, llamando la atención la ausencia de especímenes correspondientes a Lama guanicoe.

Se registró una baja frecuencia $(7,4 \%)$ de modificaciones antrópicas en los especímenes para los tres niveles estratigráficos, siendo más abundantes en el nivel $3(4,5 \%)$. Un $16,6 \%$ de las marcas culturales fueron realizadas indudablemente con instrumentos de metal como cuchillos, hachas/machetes y serruchos, observadas en su gran mayoría en 
los especímenes del nivel 3 -SA, SD y SE. Los especímenes procesados corresponden en gran medida a mamíferos indeterminados seguidos de Bos taurus. En relación con este último taxón se observa un predominio del costillar con evidencias de modificaciones antrópicas - fracturas y huellas de corte - realizadas con instrumentos de metal. La presencia de costillas y su trozamiento en tamaños estandarizados podría estar indicando su ingreso en forma de carne salada al fuerte (Marschoff, 2007) - ver Figura 10J-. Sin embargo, en una menor proporción también se registraron otros elementos esqueletales correspondientes a este taxón, lo cual podría dar cuenta del procesamiento de los animales en el contexto ocupacional del sitio.

Un 98,4\% de los especímenes recuperados no presenta evidencias de termoalteración, aunque el SD es el que presentó una mayor variabilidad con relación a las escasas evidencias observadas de alteración térmica en el registro arqueofaunístico. En cuanto a la meteorización, se observa que el $51,1 \%$ se agrupa entre los estadios 0 y 2 . Ahora bien, el nivel 3 presentó un 41,5\% en el estadio 1, mientras que el estadio 2 predomina en los niveles 1 y 2. Esto estaría indicando un enterramiento más rápido para los especímenes depositados en los niveles inferiores y posiblemente una menor re-exposición.

En cuanto a la incidencia de agentes tafonómicos se observó que un $67,2 \%$ de los especímenes presentó evidencias de su acción, siendo las raíces el agente predominante $(92,9 \%)$ con una baja representación de la acción de carnívoros y roedores $(7 \%)$. La mayor concentración de la acción de todos estos agentes se registra en el nivel $3(39,4 \%)$. De todos los sondeos, SD es el que ha presentado una mayor incidencia de agentes naturales (26\%) seguido del SB (10,9\%), mientras que el resto de los sondeos tienen un comportamiento similar. Tomada en su conjunto, esta información indica una integridad más baja en SJ5, con respecto por ejemplo a SJ1. Asimismo, se observa que un $9,4 \%$ de los especímenes presentan manchas de carbonato probablemente debido a la presencia de valvas en el sedimento mientras que un 2,5\% presenta tinción por manganeso, por lo que la acción de la humedad sería baja. En todos los casos, la incidencia de ambos agentes químicos predomina en el nivel 3.

A diferencia del SJ1, los restos cerámicos $(2,4 \%)$ son predominantemente lozas domésticas y ladrillos, con muy baja representación de botijas (Figura 10). Si bien fue difícil asignarles cronología a las primeras por ser tiestos poco diagnósticos, sí se identificaron restos de mayólica española y de loza creamware (Figura 10A y B). En cuanto a los fragmentos de botijas, fueron identificados genéricamente a pesar de su estado y fragmentación, dado que en su mayoría presentan un tamaño menor a $10 \mathrm{~cm}^{2}$. El resto de las categorías de materiales presentaron una frecuencia muy baja (2,6\% restante), entre los que se destaca el vidrio $(0,2 \%)$ a partir de fragmentos de botellas identificados genéricamente por su mal estado de preservación — alta deshidratación (Figura 10C) - . Los materiales líticos se encuentran escasamente representados por tan solo cinco artefactos: un molino recuperado en el nivel 1 del SB y los cuatro restantes en el SD, recuperándose en el nivel 1 un percutor (Figura 10F) y en el nivel 3 un ecofacto, un chunk y una preforma posiblemente de raspador o chispero. Por último, más allá de la baja representación de metales en general, se halló un asa de bronce fundida (Figura 10E).

En cuanto al origen de la acumulación, observamos en primer lugar que la pendiente y el rodamiento no son factores determinantes en la concentración de los materiales arqueológicos. A diferencia de SJ1, los depósitos presentan una integridad más baja, aunque son relativamente estables. La composición del conjunto arqueofaunístico y la presencia de modificaciones antrópicas indican un origen cultural en gran medida. La presencia de huesos de mamíferos grandes (i.e. cetáceos, pinnípedos, Bos taurus, Sus scrofa) estaría asociada al descarte intencional y no a la re-depositación por huaqueo de las estructuras de SJ2 y SJ3, ya que huesos de este tamaño no serían descartados dentro de estructuras. Por lo tanto, si bien no descartamos la acción de agentes 
posdepositacionales - naturales y antrópicos- consideramos que la acumulación arqueológica en SJ5 estaría relacionada principalmente con actividades de descarte.

\section{Relevamientos generales}

En las diversas campañas se han realizado prospecciones de superficie buscando establecer los alcances de la ocupación colonial en la zona, así como evidencias relacionadas con ocupaciones de cazadores recolectores y ocupaciones hispano-criollas luego del abandono del Fuerte San José. En la Figura 2 está sombreada el área total de estos relevamientos efectuados mediante transectas asistemáticas de superficie, con registro y georreferenciamiento de los hallazgos. No se hallaron por el momento mayores concentraciones de materiales, restos del asentamiento colonial, evidencias del malón, ni se verificó en las inmediaciones del sitio restos de Puerto San José. Hacia el Oeste y Suroeste, no hubo ningún tipo de hallazgo y se detectaron tres sectores, uno sobre el lado Oeste de la playa (SJ6) y los dos cañadones que limitan el sitio arqueológico al Este y al Sur.

\section{Sector San José 6}

En un sector cercano a la playa sobre un cañadón se identificó una acumulación de restos materiales (Figura 2 y $5 \mathrm{E}$ ), la cual fue muestreada de forma intensiva en superficie $\left(79,5 \mathrm{~m}^{2}\right)$ mediante la recolección de materiales arqueológicos y la cuantificación de restos de ladrillos - posiblemente coloniales por sus dimensiones y características-. Pendiente arriba, sobre la ladera erosionada por un cañadón y desmoronada se registró una abundante cantidad de fragmentos de yeso, de los cuales se recolectó una muestra. Cabe mencionar que se trata de una materia prima no disponible en el área donde se encuentra emplazado el sitio arqueológico, cuya presencia en el lugar debe ser investigada teniendo en cuenta sus posibles usos.

Se recuperaron un total de 11 especímenes óseos en superficie en mal estado de preservación (i.e. Ovis sp., indeterminados y restos malacológicos). Los restos en su mayor parte se encuentran completos, miden entre 2 y $10 \mathrm{~cm}$ y la meteorización se encuentra entre los estadios 4 y 5 , dada su exposición en superficie. No se registraron evidencias de termoalteración ni modificaciones culturales. Tan sólo en dos especímenes se registró la acción de raíces y carnívoros.

Aparte de los ladrillos — 40 fragmentos mayores a $10 \mathrm{~cm}$ de lado-, se hallaron 30 fragmentos de cerámica de siglo XVIII — botijas y loza- y tres fragmentos de pipa de caolín, sin evidencias de redondeamiento ni de líquenes y con tamaños mayores a 10 $\mathrm{cm}^{2}$, resultando en un conjunto llamativo dado su lugar de depositación.

A este conjunto de superficie se le suman unos pocos fragmentos de vidrio de botella cuadrada y un conjunto de restos metálicos compuestos por clavos $(n=25)$ y fragmentos de latón $(\mathrm{n}=128)$-todos en mal estado de preservación dado el medio acuoso y salino en el que se encontraron-. Por último, se recuperaron cinco artefactos líticos correspondientes a un fragmento de laja, dos lascas, un instrumento de filo natural con filos complementarios y un posible chispero en sílice, de probable manufactura local.

\section{Cañadones}

El sitio arqueológico se encuentra limitado por los lados este y sur por dos cañadones, denominados respectivamente CE y CS (Figura 2). Si bien ambos se encontraban secos al momento de las investigaciones (verano), presentaban indicios de estar activos durante otros períodos estacionales. El CE se relevó a ambos lados y por dentro a lo 
largo de $800 \mathrm{~m}$. Se observaron artefactos y concentraciones de materiales del siglo $\mathrm{XX}$ - particularmente loza impresa -, relacionadas con el funcionamiento de la zona durante dicho siglo. Los materiales arqueológicos recolectados en su mayor parte sobre el borde de la margen este- corresponden a restos de mamíferos indeterminados, cerámica -indeterminada, gres, loza estampada whiteware y un fragmento de teja-, vidrio -indeterminado-, metales y tan solo un artefacto lítico recolectado dentro del cañadón, consistente en un fragmento de flanco de núcleo.

El CS también se caracterizó por la baja frecuencia de hallazgos arqueológicos, pero con la particularidad de asociarse algunos de ellos con la ocupación española. En cuanto a los restos óseos, se destaca el hallazgo de dos especímenes completos correspondientes a Equus ferus (tibia y metacarpianos) en el tercer estadio de meteorización. La cerámica corresponde a un fragmento de botija del siglo XVIII, al tiempo que tres de los cuatro fragmentos de vidrio recuperados corresponden a una botella redonda verde muy patinada. Por último, se relevaron también un fragmento de clavo de hierro forjado y un artefacto lítico indeterminado.

Uno de los interrogantes de las investigaciones se relaciona con el momento de origen de estas geoformas y si estuvieron presentes cuando se estableció el Fuerte San José. Es muy llamativa la ausencia de mención y/o representación cartográfica del mismo; si bien son escasas las descripciones en las fuentes históricas sobre el paisaje local, la omisión sobre la cercanía del cañadón este es significativa. Las fotografías aéreas y satelitales más antiguas corresponden a la década de 1970, cuando el cañadón ya existía con dimensiones similares a las actuales.

\section{Integración: el plano arqueológico del Fuerte San José}

La información generada hasta el momento ha permitido diferenciar seis sectores con información arqueológica, cinco de los cuales muestran un comportamiento arqueológico distintivo, lo que habilita hipotetizar sobre su funcionalidad.

En el sector SJ1 si bien no fue posible identificar restos de estructuras arquitectónicas, consideramos que el nivel gris compacto es un depósito originado a partir del aporte sedimentario de origen cultural, posiblemente como resultado de la erosión de estructuras de adobe o tapia en las proximidades. Esta interpretación se fundamenta en la distribución espacial acotada de este depósito, su relación con el parche de vegetación, la composición limo-arenosa del mismo, su característica coloración grisácea, su compactación, la presencia de valvas trituradas como posible antiplástico y los materiales coloniales. La cultura material recuperada se relaciona principalmente con restos arqueofaunísticos que incluyen especies locales y, menor medida, de origen europeo, así como vajilla colonial doméstica muy fragmentada. La misma está asociada al almacenamiento, la cocción y la presentación. No obstante, también se identificaron botellas cuadradas de ginebra, vidrios planos de farol, chisperos, clavos, un botón de uniforme y una munición de plomo, entre otras cosas. En general los materiales son pequeños, lo que dificulta profundizar en su morfología y funcionalidad. La ausencia de estructuras perecederas, así como la intervención de procesos postdepositacionales darían cuenta de la escasa estructuración del registro arqueológico en este sector. Sin embargo, la ubicación reparada de la concentración, el tipo y el estado de los restos recuperados podrían estar indicando un área de uso diario y con tránsito, indicando que este sector fue claramente relevante en términos del uso del espacio para el período colonial, siendo posiblemente el área donde se estableció el núcleo poblacional.

En SJ2 no se hallaron restos de estructuras en subsuperficie, sólo el rasgo negativo perimetral. De acuerdo a su estratigrafía podría tratarse de una zanja de origen 
antrópico excavada en el sustrato de valvas fósiles, aunque de potencia muy somera. El relleno es de origen natural producto de la acción eólica y con una escasa incorporación de materiales, a diferencia por ejemplo del foso del fuerte del sitio Floridablanca, donde se corroboró su uso como área de descarte del poblado (Senatore et al., 2008). En el caso de SJ2 dos factores podrían explicar los resultados obtenidos: 1) la presencia de una empalizada en el interior del sector impidiendo el descarte de desechos hacia la zanja, y/o 2) la definición de un sector en el sitio como área común para la acumulación de desechos. A nivel de hipótesis, consideramos entonces que SJ2 pudo haber sido el sector donde se estableció un pequeño fuerte. En cuanto a los pozos en el interior de SJ2 no se ha registrado evidencia para adscribirlos temporalmente. La evidencia arqueológica recuperada en superficie corresponde al período de ocupación del fuerte, aunque en franco estado de deterioro debido a la exposición a los agentes erosivos.

SJ3 sólo presenta el remanente de una pared de adobe muy erosionada y el pozo realizado en su interior sobre el cuál no hemos hallado información suficiente. Por su parte, SJ4 es un sector apartado, sobre-elevado, muy expuesto a agentes erosivos y con presencia de enterratorios, uno de los cuales correspondería a un poblador del fuerte (García Guraieb et al., 2017). El avance de las investigaciones permitirá establecer si corresponde efectivamente al camposanto. En caso de corroborarse esta hipótesis, estaríamos ante el descubrimiento del primer cementerio relacionado con la colonización española de la costa patagónica a fines del siglo XVIII.

El sector SJ5 se caracteriza por el predominio de restos arqueofaunísticos por sobre el resto de las categorías, particularmente en el nivel 3 de todos los sondeos. La fauna recuperada es diversa en términos taxonómicos y anatómicos con evidencias de procesamiento antrópico, particularmente en los mamíferos de porte mayor - especies europeas- y compatibles con el período de ocupación del fuerte. Lamentablemente, el resto de las categorías artefactuales en comparación se encuentran escasamente representadas. A pesar de ello, la cerámica recuperada en su mayor parte corresponde a fines del siglo XVIII y principios del siglo XIX. Si consideramos esta información en su conjunto, la cultura material recuperada guarda relación con la ocupación del fuerte, particularmente aquella proveniente del nivel 3 de los sondeos. Más allá de la acción de agentes posdepositacionales, consideramos que la acumulación arqueológica en SJ5 es resultado de actividades de descarte secundario durante la ocupación española/reocupación expedición Libanus Jones. Al respecto, es interesante resaltar que esta concentración se ubica a espaldas del núcleo poblacional; en cambio, la ladera al Sur del cerro sólo presentó hallazgos aislados.

Si bien SJ6 es un sector de difícil interpretación dada su ubicación, la ausencia de rasgos estructurales y la re-depositación de materiales por acción de derrumbes y escorrentías, el conjunto material presenta una diversidad y abundancia significativa de materiales, siendo mayormente identificados como coloniales — de fines siglo XVIII y principios del XIX - . La información suministrada por el diario de Libanus Jones puede aportar alguna pista sobre el uso y la organización del espacio de la playa, así como su reutilización en momentos posteriores (Jones 1855 en Dumrauf, 1991). Si bien los documentos históricos sobre el Fuerte San José registran un uso sostenido de la playa, estos se vinculan más a muelles naturales que funcionaron para la carga y descarga de los barcos. Finalmente, con respecto al área circundante al sitio, aunque se han hallado materiales, es muy llamativa la ausencia de modificaciones significativas, tanto coloniales como posteriores, lo cual realza el carácter discreto del uso del espacio durante la ocupación del fuerte.

\section{Palabras finales}

En tanto elusiva desde la información aportada por las fuentes históricas, la organización espacial y arquitectónica del Fuerte San José fue desde el principio de las investigaciones 
un interrogante que debía ser resuelto desde la arqueología. El abordaje metodológico no estuvo libre de desafíos, teniendo en cuenta que el Fuerte San José representa un caso atípico entre los sitios históricos, dada la escasez de estructuras arquitectónicas visibles y la segregación del archivo documental.

Como vimos, para elaborar el plano arqueológico integramos diversas líneas de evidencia que nos permitieron comprender la dinámica natural y antrópica y definir al menos seis sectores en el sitio arqueológico con una funcionalidad tentativa. Desde este punto vista, es posible generar nuevas preguntas con el objeto de profundizar el análisis líneas de evidencia específicas, así como ampliar la escala espacial en los subsiguientes trabajos de campo. Por último, queremos destacar que la re-ocupación, reclamación y huaqueo que ha sufrido el sitio desde el siglo XIX en adelante, no solo son factores a tener en cuenta a la hora de estudiar su historia de formación, sino que juegan un rol central para comprender la importancia de este sector del golfo San José en el marco de la historia ocupacional de Península Valdés.

\section{Agradecimientos}

A los evaluadores Gabriel Cocco y Luis Coll, cuyas valiosas sugerencias y correcciones contribuyeron a mejorar la calidad de este trabajo. Agradecemos la buena predisposición de los propietarios de los campos donde se ubica el sitio arqueológico: Marisol Fracasso y Arturo Garrido. A la Dra. Julieta Gómez Otero por su apoyo y colaboración. A la Dirección Investigación, Secretaría de Cultura de Chubut; Dirección General de Conservación de Áreas Protegidas, Subsecretaría de Turismo y Áreas Protegidas y a la Administración Península Valdés. Queremos agradecer la colaboración en las tareas de campo y laboratorio de: María Marschoff, Sabrina Carelli, Demian Laborde, Julieta Gómez Otero, Anahí Banegas, Ariadna Svoboda, Silvia Dahinten, Gabriela Millán, Solana García Guraieb, Jimena Alberti, Lorena L'Heureux, Carlos Belotti y Federico Scartascini. Agradecemos muy especialmente también la colaboración del Sr. Jorge Depasquali y el Lic. Bruno Sancci. Las investigaciones fueron financiadas por los siguientes proyectos: PICT 2010-0050 (2011-2012), ANPCyT; PIP 0183 (2011-2013) y PIP 0759 (2014-2016), CONICET. 


\section{Q Referencias citadas}

" Administración Área Natural Protegida Península Valdés (AAPV). (S/f). Plan de Manejo del Área Protegida Sistema Península Valdés. http://peninsulavaldes.org.ar/descargas/. (Acceso: 10 de octubre, 2017).

》 Autores varios. Sala IX, Legajos, 16-3-9, 16-3-10, 16-3-12, 16-4-1, 16-4-2, 16-4-3, 16-4-5, 16-46, 16-4-11, 16-5-1 y Sala XIII, 26-6-6. Buenos Aires: Archivo General de la Nación.

»Apolant, J. A. (1970). Operativo Patagonia. Montevideo: Letras.

»Aragón, A. (1810). Carta al Comandante del Fuerte Nuestra Señora del Carmen, 5 de septiembre, Sala X, Legajo 2-3-5. Buenos Aires: Archivo General de la Nación.

"Banegas, A, Goye, S. y Gómez Otero, J. (2015). Caracterización regional de recursos líticos en el nordeste de la provincia del Chubut (Argentina). En J. Alberti y V. Fernández (Eds.), Materias primas líticas en Patagonia. Localización, circulación y métodos de estudio de las fuentes de rocas de la Patagonia argentino-chilena. Intersecciones en Antropología, Dossier 2, 39-50.

"Barba Ruiz, L. (2000). Acontecimientos históricos de Península Valdés. Rawson: Comisión Pro-Monumentos a las gestas y primeras colonizaciones españolas del Chubut.

"Barone, R. (1987). Anatomía comparada de los mamíferos domésticos (Tomo I, fascículos I y II). Buenos Aires: Hemisferio Sur.

》Behrensmeyer, A. K. (1978). Taphonomic and Ecologic Information from Bone Weathering. Paleobiology, 4, 150-162.

》 Belardi, J. (2005). Paisajes arqueológicos: un estudio comparativo de diferentes ambientes patagónicos. Oxford: BAR International Series 1390.

" Bernard M. C. y Joiret, S. (2009). Understanding corrosion of ancient metals for the conservation of cultural. Electrochimica Acta, 54(22), 5199-5205.

" Bianchi Villelli, M. (2017). Colonialismo en Península Valdés: entre los proyectos defensivos y las tentativas comerciales (Patagonia norte, fines del siglo XVIII). Memoria Americana. Cuadernos de Etnohistoria, 25(1), 47-75.

"Bianchi Villelli, M., Buscaglia, S. y Sancci, B. (2013). Una genealogía de los planos históricos de los asentamientos coloniales del Fuerte San José, Península Valdés (Siglo XVIII). Corpus. Archivos virtuales de Alteridad Americana, 3(1), 1-14.

" Buscaglia, S. (2017). Materiality and Indigenous Agency: Limits to the Colonial Order (Argentinean Patagonia, Eighteenth-Nineteenth Centuries). International Journal of Historical Archaeology, 21(3), 641-673.

" Buscaglia, S., Alberti, J. y Álvarez, M. (2016). Techno-morphological and use-wear analyses of gunflints from Spanish colonial sites (Patagonia, Argentina). Archaeometry, 58 (Issue Suplement S1), 230-245.

" Buscaglia, S. y Bianchi Villelli, M. (2014). Informe de la $4^{\circ}$ Campaña Arqueológica al sitio Fuerte San José. Entregado a la Secretaria de Cultura de la Provincia de Chubut. Manuscrito inédito.

" Buscaglia, S. y Bianchi Villelli, M. (2016). From Colonial Representation to Materiality: Spanish Settlements on Península Valdés (Patagonian Coast, 1779-1810). Historical Archaeology, 50(2), 69-88. 
» Buscaglia, S., Bianchi Villelli, M., Starópoli, L., Bosoni, C., Carelli, S. y Alberti, J. (2012). Arqueología Histórica en Península Valdés. Primeros Abordajes Históricos y Arqueológicos al Fuerte San José (1779-1810). Revista de Arqueología Histórica Argentina y Latinoamericana, 6, 47-79.

» Cuitiño, J. I., Dozo, M. T., del Río, C. J., Buono, M. R., Palazzesi, L., Fuentes S. y Scasso, R. A. (2017). Miocene Marine Transgressions: Paleoenvironments and Paleobiodiversity. En P. Bouza y A. Bilmes (Eds.), Late Cenozoic of Península Valdés, Patagonia, Argentina (pp. 47-84). Suiza: Springer International Publishing.

» Dumrauf, C. (1991). Un precursor en la colonización del Chubut. Documentos sobre la actuación de Enrique Libanus Jones en el Chubut. Viedma: Biblioteca de la Fundación Ameghino.

» Fernández, T., Gavirati, M. yJones, N. (2008). “Eran todos campos abiertos”. Poblamiento y configuración del espacio socio-económico-cultural de Península de Valdés. Cuadernos de Historia Patagónica, 2, 71-96.

» García, P. (1780). Configuración (mapa) del Puerto de San José en la Bahía sin Fondo, situado en la latitud Sur de 42 grados 12 minutos y en longitud de 312 grados 30 minutos, meridiano de Tenerife. D. Pedro García, enero y febrero del año 1779. Remitido por Don Andrés de Viedma con carta de 4 de junio de 1780 y expediente sobre población de la Costa Patagónica, Mapas y Planos, Buenos Aires, 128. Sevilla: Archivo General Indias.

» García Guraieb, S., Tessone, A., Buscaglia, S., Crespo, C, Bianchi Villelli, M. y del Papa, M. (2017). Análisis bioarqueológico de un individuo recuperado en el Fuerte San José (Pla. Valdés, Pcia. de Chubut, 1779-1810). Revista del Museo de Antropología, 10(1), 61-76.

» Gerwin, W. y Baumhauer, R. (2000). Effect of soil parameters on the corrosion of archaeological metal finds. Geoderma, 96(1-2), 63-80.

» Gilbert, B. M., Martin, L. D. y Savage, H. G. (1981). Avian Osteology. Wyoming: B. M. Gilbert Publisher.

» Gómez Otero, J. (2006). Dieta, uso del espacio y evolución en poblaciones cazadorasrecolectoras de la costa centro-septentrional de Patagonia durante el Holoceno medio y tardío. (Tesis Doctoral inédita), Universidad de Buenos Aires, Argentina.

» Gómez Otero, J., Belardi, J. B., Súnico, A. y Taylor, R. (1999). Arqueología de cazadoresrecolectores en Península Valdés, costa central de Patagonia: primeros resultados. En J. B. Belardi, P. M. Fernández, R. A.Goñi, A. G. Guráieb, M. De Nigris (Eds.), Soplando en el Viento (pp. 393-417). Neuquén: Universidad Nacional del Comahue.

» Gómez Otero, J., Schuster, V. y Banegas, A. (2017). Archaeology of the Península Valdés: spatial and temporal variability in the human use of the landscape and geological resources. En P. Bouza y A. Bilmes (Eds.), Late Cenozoic of Península Valdés, Patagonia, Argentina (pp. 233-261). Suiza: Springer International Publishing.

» Haller, M. J. (2017). Geology of Península Valdés. En P. Bouza y A. Bilmes (Eds.), Late Cenozoic of Península Valdés, Patagonia, Argentina (pp. 23-46). Suiza: Springer International Publishing.

" Hillson, S. (1992). Mammal Bones and Teeth. An introductory guide to methods of identification. Londres: University College London.

» Lanöel, A., Barba Ruiz, L., Zapatero, J. M. y Gutiérrez Neri, A. (1974). Recopilación histórica sobre el Fuerte San José. Chubut: Comisión Pro-monumentos a las gestas y primeras colonizaciones españolas del Chubut, Dirección de Turismo.

» Luiz, M. T. (2006). Relaciones fronterizas en Patagonia. La convivencia hispano-indígena afines del período colonial. Ushuaia: Asociación Hanis, Universidad Nacional de la Patagonia San Juan Bosco. 
» Marschoff, M. (2007). Gato por Liebre. Prácticas Alimenticias en Floridablanca. Buenos Aires: Editorial Teseo.

" Mengoni Goñalons, G. (1999). Cazadores de guanacos de la estepa patagónica. Buenos Aires: Sociedad Argentina de Antropología.

» Millán, A. G. y Dahinten, S. L. (2014a). Informe bioarqueológico de los restos óseos del Fuerte San José (Península Valdés). Informe $\mathrm{N}^{\circ}{ }_{1}$. Puerto Madryn. Manuscrito inédito.

» Millán, A. G. y Dahinten, S. L. (2014b). Informe bioarqueológico de los restos óseos del Fuerte San José (Península Valdés). Informe $\mathrm{N}^{\circ}$ 2. Puerto Madryn. Manuscrito inédito.

» Moreno, E. y Videla, B. (2008). Rastreando ausencias: la hipótesis del abandono del uso de los recursos marinos en el momento ecuestre en la Patagonia continental. Magallania, 36(2), 91-104.

» Nuviala, V. (2008). Materializando Identidades en Floridablanca. Los Artefactos de Uso Personal en la Comunicación No Verbal de las Identidades (Patagonia, Siglo XVIII). (Tesis de Licenciatura inédita), Universidad de Buenos Aires, Argentina.

» Pacheco Torres, V. R., Altamirano Enciso, A. y Guerra Porras, E. (1986). The Osteology of South American Camelids. Los Ángeles: University of California.

»Senatore, M. X. (2007). Arqueología e Historia en la Colonia Española de Floridablanca. Patagonia, Siglo XVIII. Buenos Aires: Editorial Teseo.

»Senatore, M. X., Marschoff, M., Bianchi Villelli, M., Buscaglia, S., Nuviala, V., Bosoni, C. y Starópoli, L. (2008). Una Arqueología de las Prácticas Cotidianas en Floridablanca (Patagonia, Siglo XVIII). En Borrero, L. A y Franco, N. V. (Comps.) Arqueología en el extremo sur del continente Americano (pp. 81-117). Buenos Aires: Dunken.

»Sin autor. (2003). Suplemento ilustrado Golfo Nuevo. Álbum Biográfico. Puerto Madryn: Imprenta Golfo Nuevo.

»Scartascini, F. (2018). Informe sobre los peces procedentes del sector SI5, Fuerte San José (Península Valdés, Chubut). San Carlos de Bariloche. Manuscrito inédito.

»Soler, M. y García, P. (1779). Informe de Manuel Soler y Pedro García. Fuerte San José, octubre 1779. Audiencia de Buenos Aires, 326. Folios 1039-1050. Sevilla: Archivo General de Indias.

»Viedma, A. (1779). Carta al Virrey J. J. Vértiz, Buenos Aires, 25 de agosto, Sala IX, Legajo 23-10-3. Buenos Aires: Archivo General de la Nación. 